University of Louisville

ThinkIR: The University of Louisville's Institutional Repository

Electronic Theses and Dissertations

$5-2020$

\title{
Addition of Fermentation Experiment to Unit Operations \\ Laboratory
}

Jeremy T. Rone

University of Louisville

Follow this and additional works at: https://ir.library.louisville.edu/etd

Part of the Biochemical and Biomolecular Engineering Commons

\section{Recommended Citation}

Rone, Jeremy T., "Addition of Fermentation Experiment to Unit Operations Laboratory" (2020). Electronic Theses and Dissertations. Paper 3351.

https://doi.org/10.18297/etd/3351

This Master's Thesis is brought to you for free and open access by ThinkIR: The University of Louisville's Institutional Repository. It has been accepted for inclusion in Electronic Theses and Dissertations by an authorized administrator of ThinkIR: The University of Louisville's Institutional Repository. This title appears here courtesy of the author, who has retained all other copyrights. For more information, please contact thinkir@louisville.edu. 
By

Jeremy Rone

B.S., University of Louisville, 2019

\begin{abstract}
A Thesis
Submitted to the Faculty of the

University of Louisville
\end{abstract}

J.B. Speed School of Engineering

as Partial Fulfillment of the Requirements

for the Professional Degree

\title{
MASTER OF ENGINEERING
}

Department of Chemical Engineering

May 2020 
Submitted by:

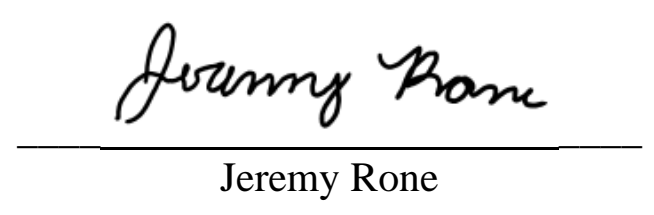

A Thesis Approved On

April 24, 2020

(Date)

by the Following Reading and Examination Committee:

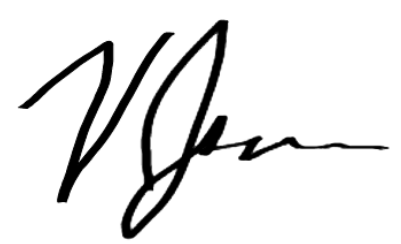

Dr. Vance Jaeger, Thesis Director

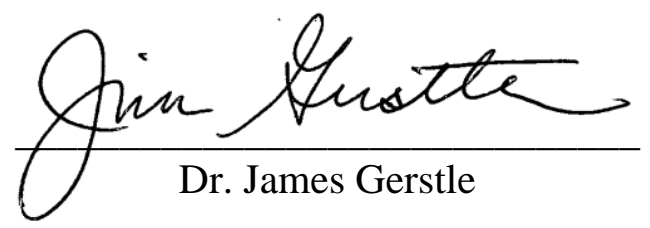

Patricia A \& Ralstoro

Dr. Patricia Ralston 


\section{ACKNOWLEDGEMENTS}

I would like to thank the members of my thesis committee, Dr. Vance Jaeger, Dr. Jim Gerstle, and Dr. Pat Ralston, for supporting me through my graduate career and working with me to improve the quality of my thesis. I would especially like to thank Dr. Jim Gerstle for allowing me to be a TA for the Unit Ops Lab Courses and for allowing me to perform the recommended fermentation experiment during the Spring 2020 semester.

I would also like to thank the Chemical Engineering faculty at the University of Louisville and my family. The Chemical Engineering faculty taught me many valuable lessons, both inside and outside the classroom. My family supported me and encouraged me to succeed throughout my undergraduate and graduate careers. 


\begin{abstract}
With the growth of the distillery and brewery industries and the potential jobs created for chemical engineers, it is imperative to equip the chemical engineering graduates from the University of Louisville with knowledge of bioreaction kinetics and experience in performing calculations to solve for concentration profiles and reaction rates. To accomplish this, it is recommended to add a fermentation experiment to the Unit Operations Laboratory II course.

Four groups of students from the Spring 2020 Unit Operations Laboratory II course performed the fermentation experiment. They were able to successfully complete all lab requirements as well as analyze the results and compare them to expected outcomes. The students drew conclusions on how different operating conditions affected the fermentation of sugars and supported their claims by citing journals and reports. Following the success from the fermentation experiment, it is recommended to add the experiment to the Unit Operations Laboratory II course. Future students who complete this experiment will be able to perform analyses and calculations similar those performed in the distillery and brewery industries.
\end{abstract}




\section{TABLE OF CONTENTS}

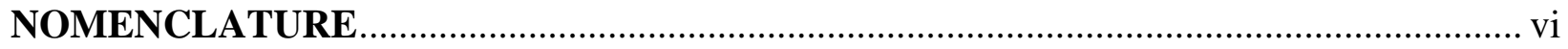

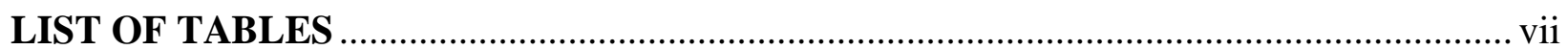

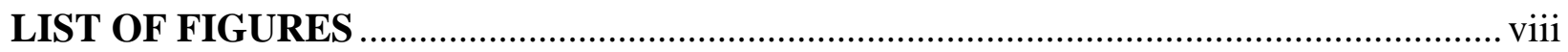

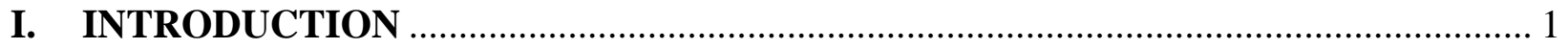

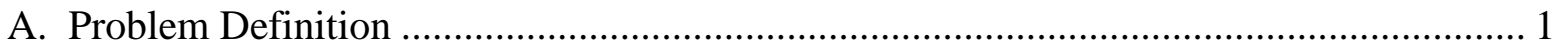

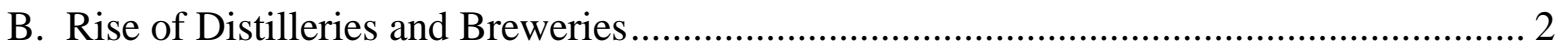

C. Background of the Unit Operations Laboratory ............................................................ 3

D. Purpose of the Fermentation Experiment ………………............................................ 4

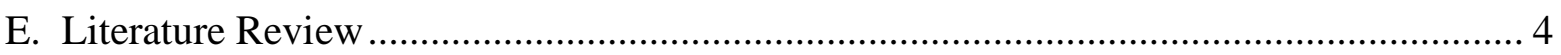

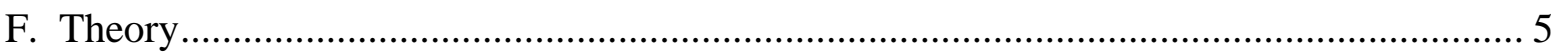

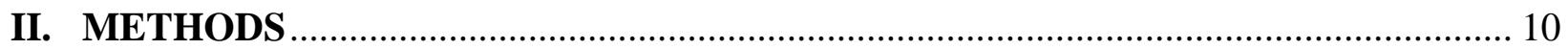

A. Evolution of Design ............................................................................................... 10

B. Materials, Instrumentation, and Equipment ................................................................. 11

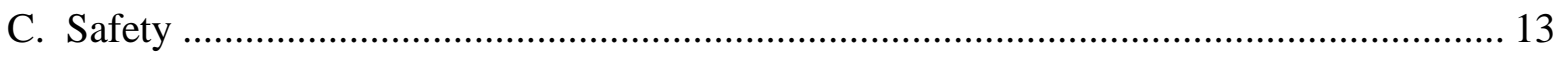

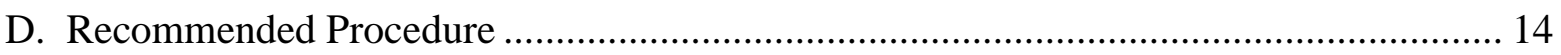

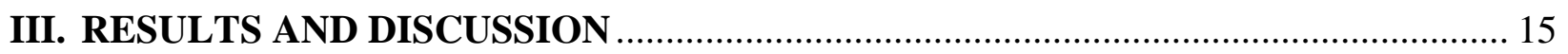

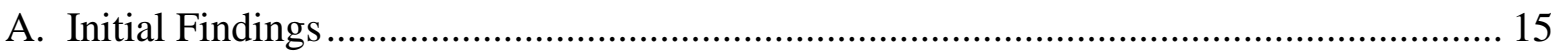

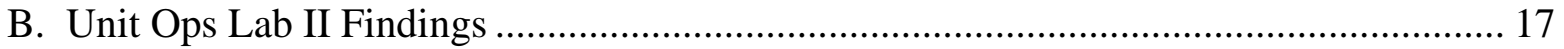

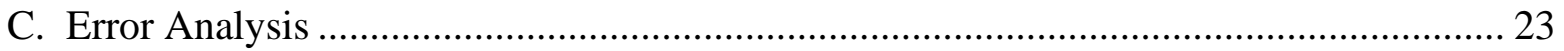

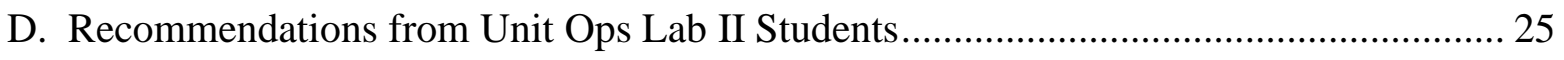

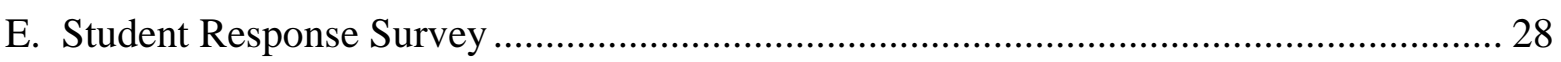

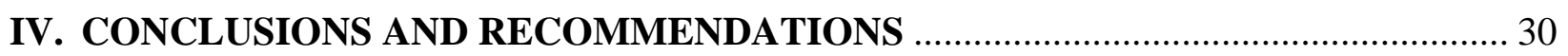

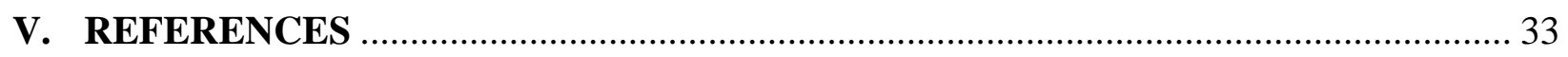

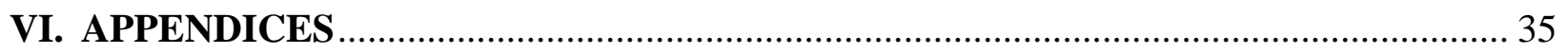

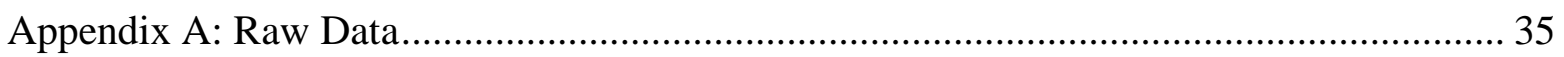

Appendix C: Yeast Cell Absorbance-Concentration Curves.................................................... 41

Appendix D: Recommended Procedure for Unit Ops Lab II ............................................ 42

Appendix E: Fermentation Procedure Available to Students During the Spring 2020 Unit

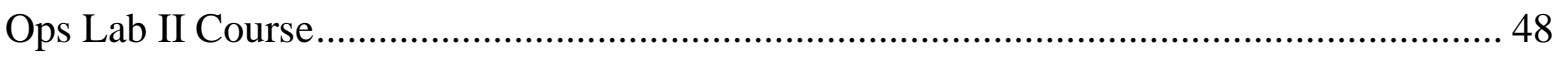




\section{NOMENCLATURE}

\begin{tabular}{|c|c|}
\hline Abbreviation/Symbol & Meaning \\
\hline ABET & Accreditation Board for Engineering and Technology \\
\hline $\mathrm{ABW}$ & Alcohol by weight, g ethanol/100 g beer \\
\hline ATP & Adenosine triphosphate \\
\hline Brix \% & A measurement of refractive index, unitless \\
\hline $\mathrm{C}_{\mathrm{c}}$ & Cell concentration, $\mathrm{g} / \mathrm{L}$ \\
\hline $\mathrm{C}_{\mathrm{p}}$ & Product concentration, $\mathrm{g} / \mathrm{L}$ \\
\hline $\mathrm{C}_{\mathrm{p}}^{*}$ & Product concentration at which all metabolism stops, $\mathrm{g} / \mathrm{L}$ \\
\hline $\mathrm{C}_{\mathrm{s}}$ & Substrate concentration \\
\hline DI & Deionized \\
\hline DME & Dry malt extract \\
\hline HPLC & High Performance Liquid Chromatography \\
\hline Initial $\mathrm{SG}^{\circ} \mathrm{P}$ & ${ }^{\circ} \mathrm{P}$ of the beer at the initial SG, unitless \\
\hline $\mathrm{k}_{\mathrm{d}}$ & Natural death rate constant, $\mathrm{h}^{-1}$ \\
\hline $\mathrm{k}_{\mathrm{obs}}$ & Product inhibition factor, unitless \\
\hline $\mathrm{K}_{\mathrm{s}}$ & Monod constant, $\mathrm{g} / \mathrm{L}$ \\
\hline $\mathrm{m}$ & $\begin{array}{l}\text { Mass of substrate consumed for maintenance per mass of cells per } \\
\text { time, } g \text { substrate/g cells } \cdot h\end{array}$ \\
\hline $\mathrm{n}$ & Empirical constant \\
\hline${ }^{\circ} \mathrm{P}$ & Degrees Plato, a measurement of refractive index, unitless \\
\hline$r_{d}$ & Cell death rate, $\mathrm{g} / \mathrm{L} \cdot \mathrm{h}$ \\
\hline$r_{g}$ & Cell growth rate, $\mathrm{g} / \mathrm{L} \cdot \mathrm{h}$ \\
\hline $\mathrm{r}_{\mathrm{sm}}$ & Rate of substrate consumption for maintenance, $\mathrm{g} / \mathrm{L} \cdot \mathrm{h}$ \\
\hline $\mathrm{RE}$ & Real Extract, unitless \\
\hline RPM & Rotations per minute \\
\hline SG & Specific gravity, unitless \\
\hline TA & Teaching assistant \\
\hline UCI & University of California, Irvine \\
\hline Unit Ops Lab & Unit Operations Laboratory \\
\hline $\mathrm{Y}_{\mathrm{c} / \mathrm{s}}$ & Yield coefficient of cells to substrate \\
\hline $\mathrm{Y}_{\mathrm{p} / \mathrm{s}}$ & Yield coefficient of product to substrate \\
\hline$\mu_{\max }$ & Maximum specific growth reaction rate, $\mathrm{h}^{-1}$ \\
\hline
\end{tabular}




\section{LIST OF TABLES}

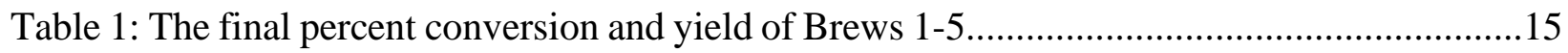

Table 2: The changed parameters of the Unit Ops Lab II brews..............................................18

Table 3: The final percent conversion and yield of the Unit Ops Lab II brews.............................18

Table 4: The $\mu_{\max }$ values of the Unit Ops Lab II brews........................................................23

Table 5: Maximum possible percent error of Brew 6 caused from the refractometer....................24

Table 6: Results from the Student Response Survey .................................................................28

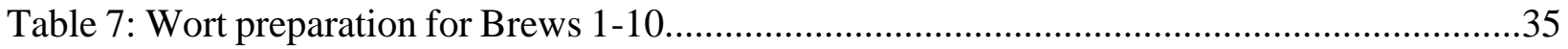

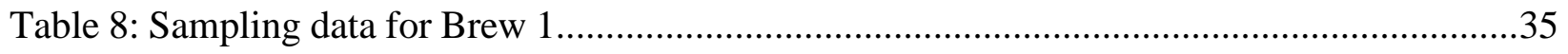

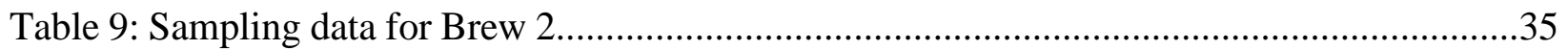

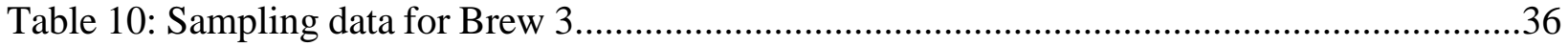

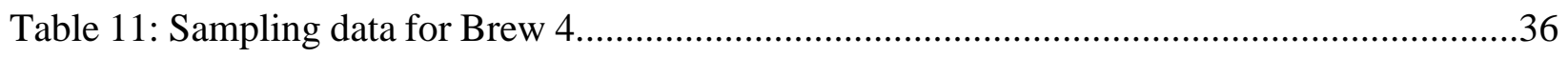

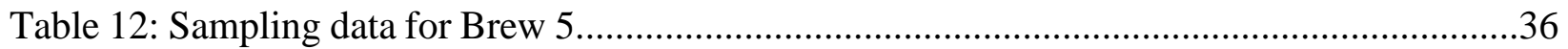

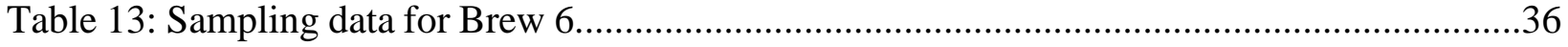

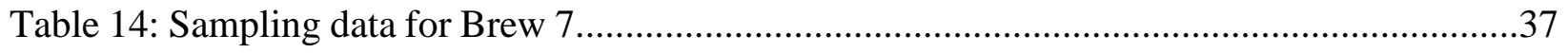

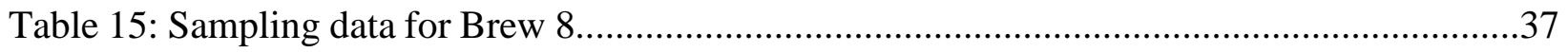

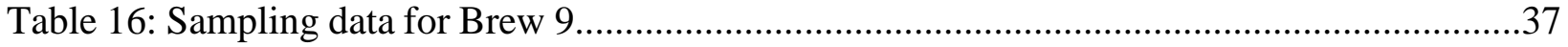

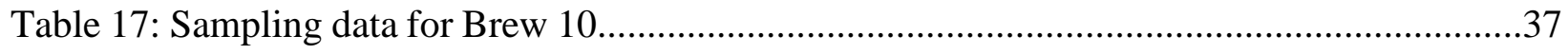




\section{LIST OF FIGURES}

Figure 1: The set-up of equipment needed for the brewing of the beer.....................................11

Figure 2: Glucose concentration over time data obtained from Brews 1-5 in Fall 2019................16

Figure 3: Ethanol concentration over time data obtained from Brews 1-5 in Fall 2019.................16

Figure 4: Glucose concentration over time data obtained from Brews 6-10 in the Spring 2020 Unit Ops Lab II course......

Figure 5: Ethanol concentration over time data obtained from Brews 6-10 in the Spring 2020 Unit Ops Lab II course.....

Figure 6: Yeast cell concentration over time data obtained from Brews 6-10 in the Spring 2020 Unit Ops Lab II course. .20 


\section{INTRODUCTION}

\section{A. Problem Definition}

In the Spring of their third year, undergraduate chemical engineering students at the University of Louisville will typically take the Kinetics and Chemical Reactors course. This course first teaches students basic kinetics for batch and flow reactors, covering rate laws and mass balance equations at isothermal conditions. The course then moves on to topics such as enzymatic reactions and nonisothermal conditions. However, bioreaction kinetics are only briefly covered, meaning that students do not learn how these reactions occur and the underlying kinetic models for these reactions.

With the growth of distilleries and breweries in Kentucky and surrounding states including Illinois, Indiana, Ohio, and Tennessee, more jobs in the fermentation industry are becoming available ${ }^{1,2,3,4}$. For these job openings, chemical engineers will be among some of the most sought-after applicants. To optimize the distillation and fermentation processes for yield and quality, the operating conditions, reaction conditions, and effects of changing key parameters must be understood. Heat transfer, mass transfer, kinetics, and thermodynamics are all concepts that chemical engineers have studied, making chemical engineers the top candidates to fill positions such as master distiller and process engineer.

Since coursework in the Chemical Engineering department at the University of Louisville does not directly cover fermentation and bioreaction kinetics, graduates may be deterred from applying to these job openings, opting instead for jobs in industries where they are more comfortable. If the undergraduate curriculum were improved by exposing students to bioreactions and the modeling 
equations that govern such reactions, then the students would be more competitive and marketable in the distillery and brewery industries.

\section{B. Rise of Distilleries and Breweries}

Throughout Kentucky and surrounding states, both distilleries and breweries have recently seen substantial growth in production and employment. In 2014, there were only 18 craft breweries open in Kentucky while in 2018, this number had grown to $61^{1}$. In 2016 alone, the brewing industry in Kentucky saw a $25 \%$ increase in total workforce coming from the rise in the craft beer market and realized a $\$ 495$ million economic impact throughout the state ${ }^{2}$. Similar growth has also been seen throughout Illinois, Indiana, Ohio, and Tennessee, with a total of 467 more breweries being operated in 2018 than in $2014^{1}$. Distilleries in Kentucky have also seen a rise in both output and employment opportunities. From 2009 to 2019, the number of operational distilleries in the state grew from 19 to 68 . These new distilleries have doubled the number of jobs in the distilling industry and have increased the industry's annual economic output by more than $\$ 3$ billion ${ }^{3,4}$. In both the distillery and brewery industries, production, jobs, and capital have been rapidly growing. Assuming that the composition of the workforce has remained the same, then the number of engineering jobs has also doubled. Since this growth is not expected to stop within the next few years ${ }^{4}$, new chemical engineering graduates from the University of Louisville will have more opportunities to start their career.

Fermentation is not only applicable to breweries and distilleries. Other industries, such as biofuels and pharmaceuticals, also rely on fermentation to create products. Research is ongoing to increase the yield and efficiency of converting the carbohydrates in algae into bioethanol and biodiesel. The demand of edible food oils has put limitations on using corn, soybean, and sugarcane as feedstock for biofuels, shifting the focus to algae ${ }^{5}$. The pharmaceutical industry has started using microbial 
fermentation to grow specific organic molecules. The microbial fermentation is more viable than mammalian cell cultures because with fermentation, more chemical compounds can be produced ${ }^{6}$.

\section{Background of the Unit Operations Laboratory}

In the Fall 2019 and Spring 2020 semesters, the Unit Operations Laboratory (Unit Ops Lab) course at the University of Louisville was divided into two separate lab and completed by chemical engineering students in their senior year. There were four main goals of the Unit Ops Lab courses: namely (1) to conduct the labs in a safe manner to teach students the importance of safety in industry, (2) to improve the communication skills of the students, (3) to provide the students with hands-on experience with equipment and procedures that will be seen in industry, and (4) to educate students in the analysis of experimental data ${ }^{7}$.

In the first semester of the Unit Ops Lab (Unit Ops I), students improved their communication skills as they wrote both individual and group lab reports detailing the experiments they completed as a group and the key findings from the data collected. As this was one of the first technical writing courses the students had completed, increased attention was paid to improving written communication skills. During Unit Ops I, the experiments focused on fluid flow and heat transfer and allowed students to gain experience working with equipment such as pumps, packed towers, and heat exchangers ${ }^{7,8}$. In individual and group reports, students must explained the main safety considerations, performed error analysis, and calculated values associated with established models and theory.

In the second semester of the Unit Ops Lab (Unit Ops Lab II), students wrote group reports and individual executive summaries. During Unit Ops II, the experiments focused on mass transfer, separation operations, and kinetics and allowed students to gain experience working with equipment such as distillation columns, tray dryers, and packed bed reactors ${ }^{9}$. When writing lab 
reports, students were still expected to detail the safety factors, however, more focus was put on the error analysis section, specifically how the error would propagate throughout the calculations.

\section{Purpose of the Fermentation Experiment}

The purpose of the fermentation experiment was to expose students to the fundamentals of bioreactions, a primary piece of lab-scale equipment from the fermentation industry, and the calculations needed to solve for kinetic parameters, yields, and conversion. According to the Accreditation Board for Engineering and Technology (ABET), the concept of bioreaction kinetics is not required for a chemical engineering program to receive accreditation ${ }^{10}$; however, having this knowledge would give the chemical engineering graduates from the University of Louisville applicable experience to pursue careers in the distillery and brewery industries. Practical experience came from both the sampling taking place throughout the experiment and the calculations and analysis to interpret the data collected.

Since the fermentation experiment focuses on kinetics, it would take place during the Unit Ops Lab II course. To complete the lab objectives, certain requirements would have to be met, including calculating yield and conversion of glucose to ethanol, comparing the concentration profiles and kinetics between different fermentation conditions, and modeling the yeast growth rate using the Monod equation.

\section{E. Literature Review}

The fermentation experiment was based on a similar experiment designed by the Department of Biochemistry and Molecular Biology at the University of California, Irvine (UCI) ${ }^{11}$. However, the proposed fermentation experiment focused more on the kinetics of fermentation and was designed to be completed in a shorter time period to fit the schedule of the Unit Ops Lab course. 
The learning objectives of the UCI Microbiology Lab were as follows: "(1) describe the role of the brewing ingredients, including malt extract, yeast, and hops, (2) describe the different stages in the brewing process, (3) describe how beer gets its color and how this color can be measured, (4) calculate the alcohol content of a beer based on initial and final specific gravity, (5) predict how a beer's characteristics might change if its ingredients or brewing conditions are altered, and (6) apply the scientific method to the brewing process"11. These learning objectives were accomplished by students selecting one of the ingredients to vary and designing an experiment to test a hypothesis about how the variable will change the beer's characteristics. During the first week of the UCI experiment, the students brewed the beer, including the change to the independent variable, and recorded the initial specific gravity of their beer. In the second week of the experiment, the students transferred their fermented beer into a new container with the addition of a sugar solution to carbonate the beer. During the third week, the students then sampled their carbonated beer. Then the students of UCI determine the calorie content, the percent alcohol, the $\mathrm{pH}$, and the style of beer created ${ }^{12}$.

\section{F. Theory}

The fermentation experiment used the theory and methods outlined in Elements of Chemical Reaction Engineering, Fifth Edition ${ }^{13}$. Constants used in the Monod equation and other kinetic equations were also found in this text. The constants in the Monod equation included the Monod constant, $\mathrm{K}_{\mathrm{s}}$ at a value of $1.7 \mathrm{~g} / \mathrm{L}$, the product concentration at which all metabolism stops, $\mathrm{C}_{\mathrm{p}}{ }^{*}$, at a value of $93 \mathrm{~g} / \mathrm{L}$, and an empirical constant, $\mathrm{n}$, at a value of 0.52 . Other constants used included the natural death rate, $\mathrm{k}_{\mathrm{d}}$, at a value of $0.01 \mathrm{~h}^{-1}$ and the maintenance utilization term, $\mathrm{m}$, of $0.03 \mathrm{~g}$ substrate/g. cells $\cdot \mathrm{h}$. 
During glucose fermentation, yeast cells break down glucose molecules, and energy is transferred to the form of adenosine triphosphate (ATP). ATP is used by the cells to grow and reproduce. The cycle that forms ATP only partially oxidizes the glucose, allowing ethanol and carbon dioxide to be produced as by-products ${ }^{14}$.

There are four stages of yeast cell growth that are known as the lag phase, exponential growth phase, stationary phase, and the death phase. During the lag phase, yeast cells adjust to their new environment and little growth is observed. The exponential growth phase is when the yeast cells start to quickly grow as they metabolize sugars and start producing ethanol. Net cell growth rate is equal to zero during the stationary phase, as the substrate concentration starts to deplete. The death phase then starts as the substrate concentration is too low to support the yeast cell concentration and the toxic environment caused from ethanol formation starts killing the yeast cells $^{13}$.

For this fermentation experiment, the glucose was provided by a dry malt extract (DME) of malted barley. The DME was boiled to breakdown the malt into fermentable sugars that the yeast cells could use and to sterilize the yeast's growth medium. The fermentable sugars in the wort were glucose, fructose, sucrose, maltose, and maltotriose ${ }^{15}$. The yeast cells used were Baker's yeast cells (Saccharomyces cerevisiae). Baker's yeast cells produce the enzymes invertase and $\alpha$-glucosidase to convert other fermentable sugars in the DME to glucose ${ }^{15}$.

The growth rate of the cells throughout the fermentation process, considering product inhibition, could be modeled by the empirical form of the Monod equation ${ }^{13}$

$$
r_{g}=k_{o b s} \frac{\mu_{\max } C_{s} C_{c}}{K_{s}+C_{s}}
$$


where $\mathrm{C}_{\mathrm{c}}$ is the cell concentration, $\mathrm{C}_{\mathrm{s}}$ is the substrate concentration, $\mathrm{k}_{\mathrm{obs}}$ is the product inhibition factor, $\mathrm{K}_{\mathrm{s}}$ is the Monod constant, $\mathrm{r}_{\mathrm{g}}$ is the cell growth rate, and $\mu_{\max }$ is the maximum specific growth reaction rate. The product inhibition factor could be obtained from Equation $2^{13}$

$$
k_{o b s}=\left(1-\frac{C_{p}}{C_{p}^{*}}\right)^{n}
$$

where $\mathrm{C}_{\mathrm{p}}$ is the product concentration, $\mathrm{C}_{\mathrm{p}}{ }^{*}$ is the product concentration at which all metabolism stops, and $\mathrm{n}$ is an empirical constant.

Yeast cells die naturally over time or when exposed to a toxic substance in high enough concentrations. Since the inhibition from ethanol on the growth of yeast was accounted in the Monod equation, only natural death of the yeast cells needed to be considered in the cell death rate. The cell death rate was given by Equation $3^{13}$

$$
r_{d}=k_{d} C_{c}
$$

where $k_{d}$ is the natural death rate constant and $r_{d}$ is the cell death rate.

When the cells used the substrate as an energy source instead of converting the substrate to products, the cells were maintaining homeostasis. The rate of substrate consumption for maintenance was given in Equation $4^{13}$

$$
r_{s m}=m C_{c}
$$

where $\mathrm{m}$ is the mass of substrate consumed for maintenance per mass of cells per time and $\mathrm{r}_{\mathrm{sm}}$ is the rate of substrate consumption for maintenance. 
To relate the amount of yeast cells produced to the amount of substrate consumed and amount of product produced, yield coefficients needed to be calculated. The yield coefficient of cells and substrate was given by Equation $5^{13}$

$$
Y_{c / s}=-\frac{\Delta C_{c}}{\Delta C_{s}}
$$

and the yield coefficient of product and cells was given by Equation $6^{13}$.

$$
Y_{p / c}=\frac{\Delta C_{p}}{\Delta C_{c}}
$$

By combining the kinetic relationships with the yield coefficients, a mass balance equation could be derived. Integrating the mass balance using Polymath resulted in concentration profiles for the respective chemical species over time.

Theoretical profiles were compared to experimental values obtained throughout the fermentation process. To determine the amount of substrate present in the beer as it ferments, the Brix \%, a measurement of refractive index, could be converted to specific gravity (SG), the ratio of the beer's density to water's, which could further be converted to a concentration. While the Brix \% measures the weight percent of a sucrose solution, industry still uses the Brix \% scale on other sugar solutions. When the Brix \% scale is used for other sugar solutions, the measurement is called the "apparent Brix \%" and is a relative value ${ }^{16}$. The initial Brix \% was converted to an initial SG by Equation $7^{17}$.

$$
S G=\frac{\text { Brix } \%}{258.6-227.1\left(\frac{\text { Brix } \%}{258.2}\right)}+1
$$


As ethanol was produced, the Brix \% value was affected by both the decrease in glucose and the increase in ethanol. Therefore, Equation 7 cannot be used to determine the SG of the beer after the initial sample. To determine the SG for the samples taken throughout the experiment, a Brix \% to SG conversion calculator located on the Brucrafter website ${ }^{17}$ was used.

To determine the amount of ethanol produced throughout the fermentation process, the alcohol by weight $(\mathrm{ABW})$, in grams of ethanol per 100 grams of beer, was approximated by Equation $8^{12}$

$$
A B W=\frac{\left(\text { Initial } S G^{\circ} P\right)-R E}{2.0665-0.010665\left(\text { Initial } S G^{\circ} P\right)}
$$

where Initial $\mathrm{SG}^{\circ} \mathrm{P}$ is the degrees Plato, a measurement of refractive index, of the beer at the initial SG and RE is the Real Extract, a SG correction factor for ethanol. The SG was converted to ${ }^{\circ} \mathrm{P}$ by Equation $9^{12}$

$$
{ }^{\circ} P=-463.37+668.72(S G)-205.35(S G)^{2}
$$

and the RE of a sample was approximated by Equation $10^{12}$.

$$
R E=0.1808\left({\text { Initial } \left.S G^{\circ} P\right)}^{\circ}+0.8192\left(\text { Sample } S G^{\circ} P\right)\right.
$$

The experimental yeast cell concentration was found using the Beer-Lambert Law, which states that absorbance is proportional to concentration. The absorbance of the wort was recorded at varying wavelengths and the maximum absorbance value was obtained at $360 \mathrm{~nm}$. Calibration curves were then created at $360 \mathrm{~nm}$ with known yeast cell concentrations. It should be noted that at absorbances above 1.0, deviations are seen in the linear relationship of concentration and absorbance. 


\section{METHODS}

\section{A. Evolution of Design}

The first iteration of this fermentation experiment was a scale-up of the UCI Microbiology Lab ${ }^{12}$. Instead of fermenting $500 \mathrm{~mL}$ of beer, the fermentation experiment started with half a gallon of water, resulting in around $1200 \mathrm{~mL}$ of fermentable beer after the boiling. The DME, hops, and proportionally scaled to the water, with the mass of DME increasing from $71 \mathrm{~g}$ to $269 \mathrm{~g}$, the mass of hops increasing from $1.5 \mathrm{~g}$ to $5.68 \mathrm{~g}$, and the mass of yeast increasing from $0.4 \mathrm{~g}$ to $1.51 \mathrm{~g}$. This first iteration used both a hydrometer and a hand-held refractometer to measure the SG of the beer as it fermented. The goal of this first attempt was to measure concentration profiles of glucose and ethanol of brews and compare the results from the hydrometer and the refractometer. After analyzing three experiments using UCI's concentrations for DME, hops, and yeast, it was determined that the amount of yeast was too high. Brix \% dropped too quickly, and sampling twice a day was not sufficient to develop concentration profiles that matched theoretical results.

The next iteration of the fermentation experiment lowered the amount of yeast, from $1.51 \mathrm{~g}$ to 0.3 $\mathrm{g}$, while the amount of DME and hops remained the same. The same sampling method was used, measuring the SG with a hydrometer and the Brix \% with the hand-held refractometer twice a day. Lowering the initial yeast concentration slowed the fermentation process well enough that the samples gave reasonable looking concentration profiles when comparing them to Fogler ${ }^{13}$. However, there were still issues with this design of the Fermentation Experiment. Sampling with the hydrometer required a relatively large volume of beer to be taken from the fermenter to measure SG. To maintain the volume of beer, this sample was then poured back into the fermenter and then 
resealed to continue fermenting. Sampling with this method greatly increased the risk of contaminating the beer with bacteria that would compete with the yeast for nutrients.

The third iteration of the fermentation experiment removed hydrometer sampling and the hops and added sampling the beer with a spectrophotometer to measure yeast cell concentration. The third iteration was used by four groups of students in the Unit Ops Lab II Spring 2020 course. The procedure is included in Appendix E: Fermentation Procedure Available to Students During the Spring 2020 Unit Ops Lab II Course. The students measured absorbance of the beer to determine yeast concentration as well as sampled for Brix \% to determine glucose concentration. The students then followed the Equations listed in the Theory section and were able to create concentration profiles and yeast cell growth rate curves and determine the yield and percent conversion.

\section{B. Materials, Instrumentation, and Equipment}

Figure 1 shows how the equipment was set-up during the Unit Ops II brews. The pot containing the boiling wort is in the middle and the fermenter jar and airlock are on the left side.



Figure 1: The set-up of equipment needed for the brewing of the beer. 
The materials, instrumentation, and equipment provided to the students to complete the fermentation experiment were as follows:

\section{Materials:}

- Water (DI and tap)

- Ice

- Concentrated Brewers Wort Pale Ale Dry Malt Extract

- Nottingham ale yeast

- Star San sanitization solution

\section{Instrumentation:}

- Zuzi Spectrophotometer Model 4201/20

- $\quad$ Eppendorf Centrifuge 5702

- Agtec Portable Refractometer with Copper ATC (0-32 Brix \%)

- Clip-on thermometer

- Scales

\section{Equipment:}

- 1-gallon glass fermenter

- Airlock

- Hot plate

- Stir spoon

- 4.5-cup measuring cup

- 3.5-quart enameled steel straight pot 
- 12-quart bucket

- 250-mL beaker

- Cuvettes

- $\quad$ 15-mL centrifuge tubes

- Micropipette

- 50-mL sample tubes

- $\quad 50-\mathrm{mL}$ disposable serological pipettes

- Heat resistant gloves

\section{Safety}

Safety and the wellbeing of the students and instructors of the Unit Ops Lab courses are always of utmost importance. With this in mind, potential hazards and ways to prevent harm have been identified for the fermentation experiment. The brewing of the beer involves boiling the wort on a hot plate. Students might burn themselves in a few ways: accidentally touching the hot plate or the pot, touching the handle of the pot when lifting it off the hot plate, and scalds caused by the wort boiling over if the students are not paying attention. To prevent these burn hazards, the students and Teaching Assistant (TA) must constantly monitor the boiling wort and caution must be exercised when standing near the pot. Heat resistant gloves were provided to prevent burns from lifting the pot off the hot plate.

Permission was obtained to perform this experiment on campus. The brewing and storage of alcohol on campus is not normally allowed, however, since the experiment is for academic purposes and is being supervised by University of Louisville employees, an exception was made. A sip-and-spit test for students 21 years or older was also permitted to sample the flavor of the fermented beer, but this test was not implemented. 


\section{Recommended Procedure}

The final revision for the fermentation experiment recommended for addition to the Unit Ops Lab II course is provided in Appendix D: Recommended Procedure for Unit Ops Lab II. The recommended procedure differs from the procedure given to students in the Unit Ops Lab II Spring 2020 course mainly by correcting typographical errors, defining more terms, clarifying vague references, and having additional equations added. All of these changes were made to reduce student confusion and to make the theory section as straightforward as possible. The recommended procedure also includes more lab options with additional variables the students could test, such as yeast strain and DME type. 


\section{RESULTS AND DISCUSSION}

\section{A. Initial Findings}

The first and second iterations of the fermentation experiment took place during the Fall 2019 semester. Five brews were completed, with Brews 2-5 having the same initial concentrations of DME, hops, and yeast. Brew 1, on the other hand, used a higher concentration of yeast from the UCI Microbiology Lab ${ }^{12}$. Table 1 shows the percent conversion and yield from the five initial brews and Figures 2 and 3 show the concentration profiles of glucose and ethanol, respectively. The raw data and the sample calculations used to calculate these values can be found in Appendix A: Raw Data and Appendix B: Sample Calculations.

Table 1: The final percent conversion and yield of Brews 1-5.

\begin{tabular}{|c|c|c|}
\hline Brew & Conversion & Yield, $\frac{\text { mol ethanol }}{\text { mol glucose }}$ \\
\hline Brew 1 & $83.78 \%$ & 1.579 \\
\hline Brew 2 & $75.62 \%$ & 1.573 \\
\hline Brew 3 & $74.73 \%$ & 1.574 \\
\hline Brew 4 & $75.90 \%$ & 1.574 \\
\hline Brew 5 & $75.33 \%$ & 1.572 \\
\hline
\end{tabular}

The average conversion of Brews 2-5 was $75.40 \%$ and the standard deviation was $0.43 \%$. The average yield of Brews 2-5 was 1.573 and the standard deviation was 0.00083 . From the consistent values of percent conversion and yield for Brews 2-5, it can be concluded that there was little variation in results when using the same initial concentrations of DME, hops, and yeast. This suggests that the results obtained from the fermentation experiment should be repeatable. 
Therefore, it is possible to supplement students' results with sample data if they incorrectly take a sample during the experiment.

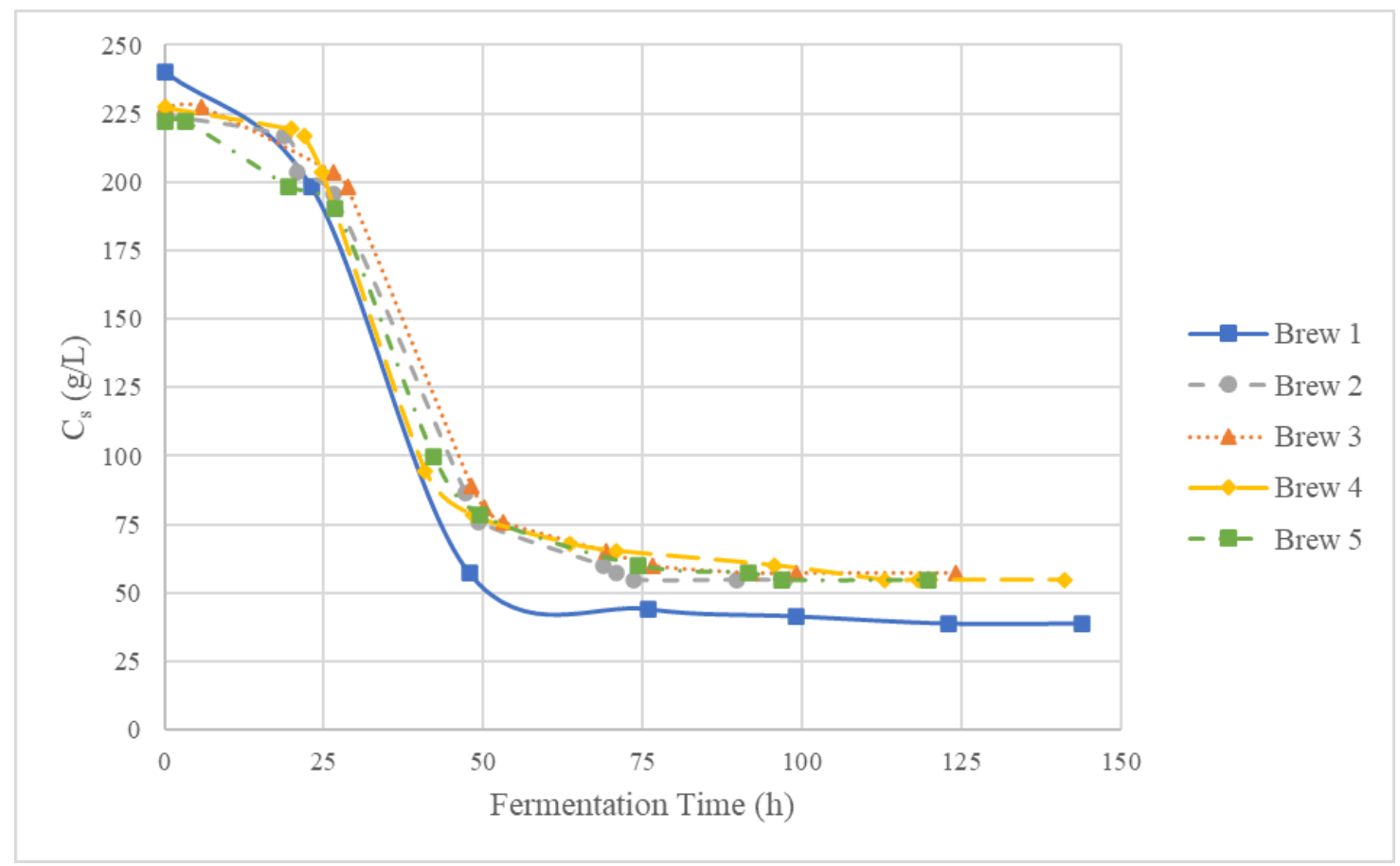

Figure 2: Glucose concentration over time data obtained from Brews 1-5 in Fall 2019.

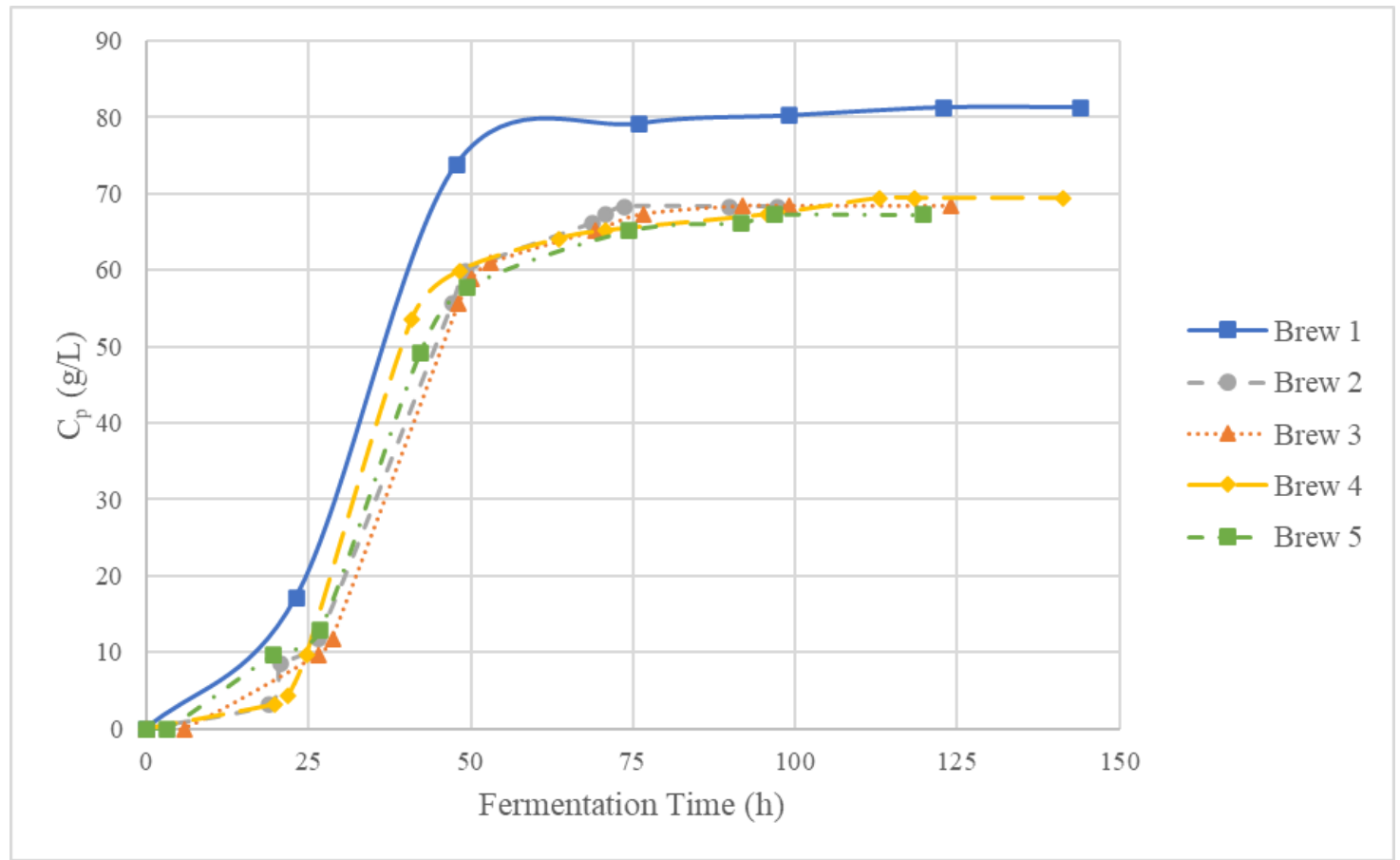

Figure 3: Ethanol concentration over time data obtained from Brews 1-5 in Fall 2019. 
It can be seen in Figure 2 that the starting substrate concentration for Brew 1 was slightly higher than the other brews. If Brew 1 used the same amount of yeast as Brews 2-5, it would be expected that the final substrate concentration would also be slightly higher for Brew 1; however, the amount of yeast in Brew 1 is approximately 3.5 times higher than the other four brews. The higher yeast concentration increases substrate consumption, resulting in a higher ethanol concentration and higher conversion. The higher ethanol concentration can be seen in Figure 3, as Brew 1 finishes fermenting with approximately $10 \mathrm{~g} / \mathrm{L}$ more ethanol than the other brews. The higher conversion is apparent in Table 1, as Brew 1 has about an $8 \%$ higher percent conversion than the other four brews. From Table 1, the yield for Brew 1 is only $0.3 \%$ higher than the yields for the other brews. More yeast did not result in a higher yield. This was due to the higher concentration of yeast also having a higher maintenance demand on the substrate. More yeast cells need to consume more glucose to maintain cell function, preventing more ethanol from being produced.

\section{B. Unit Ops Lab II Findings}

During the Spring 2020 semester, five brews were completed for the Unit Ops Lab II course, with four of the brews being completed by student groups. For these brews, hops were not added to the wort to prevent interference with spectrophotometry readings. A standard brew was completed that used the same target amounts of DME and yeast form the previous brews. A wort boil time of one hour was used and the wort was not filtered prior to fermentation. For each of the other four brews, one of these parameters were changed. The five brews of Unit Ops II are summarized in Table 2. The wort of Brew 10 was filtered before being transferred to the fermenter using coffee filters. During sampling of Brews 9 and 10, procedures were improperly followed resulting in the omission of some absorbance values. Table 3 displays the percent conversion and the yield of each of the five brews. Figures 4, 5, and 6 show the concentration profile of glucose, ethanol, and yeast 
cells, respectively. The raw data can be seen in Appendix A: Raw Data, sample calculations to find all necessary values are shown in Appendix B: Sample Calculations, and yeast cell concentration calibration curves can be found in Appendix C: Yeast Cell Absorbance-Concentration Curves.

Table 2: The changed parameters of the Unit Ops Lab II brews.

\begin{tabular}{|c|c|}
\hline Brew & $\begin{array}{c}\text { Parameter } \\
\text { Changed }\end{array}$ \\
\hline Brew 6 & Standard \\
\hline Brew 7 & $100 \%$ More Yeast \\
\hline Brew 8 & $50 \%$ Less Boil Time \\
\hline Brew 9 & 25\% More DME \\
\hline Brew 10 & Filtered Wort \\
\hline
\end{tabular}

Table 3: The final percent conversion and yield of the Unit Ops Lab II brews.

\begin{tabular}{|c|c|c|}
\hline Brew & Conversion & Yield, $\frac{\text { mol ethanol }}{\text { mol glucose }}$ \\
\hline Brew 6 & $71.89 \%$ & 1.577 \\
\hline Brew 7 & $74.74 \%$ & 1.578 \\
\hline Brew 8 & $72.03 \%$ & 1.560 \\
\hline Brew 9 & $71.08 \%$ & 1.584 \\
\hline Brew 10 & $86.27 \%$ & 1.580 \\
\hline
\end{tabular}




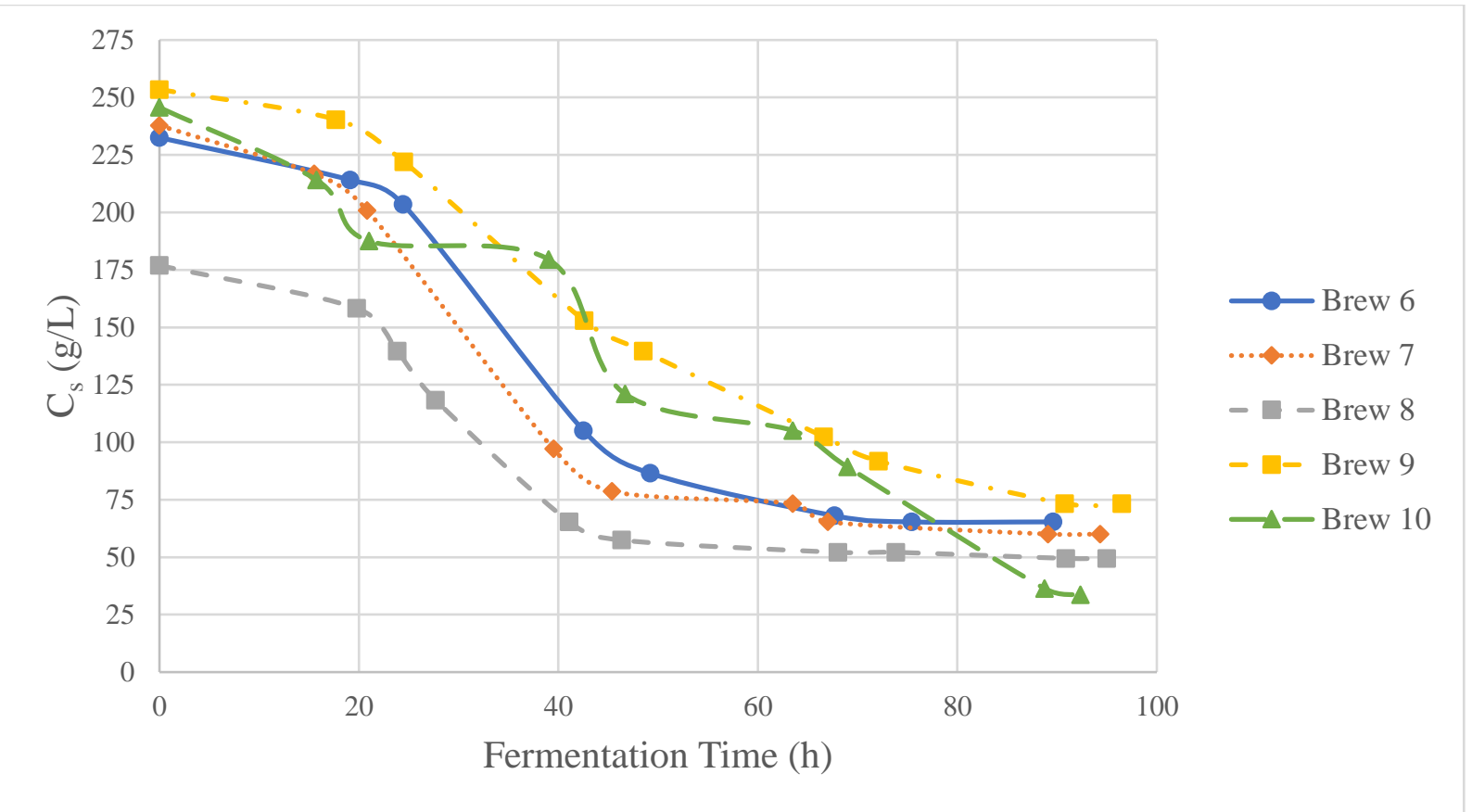

Figure 4: Glucose concentration over time data obtained from Brews 6-10 in the Spring 2020 Unit Ops Lab II course.

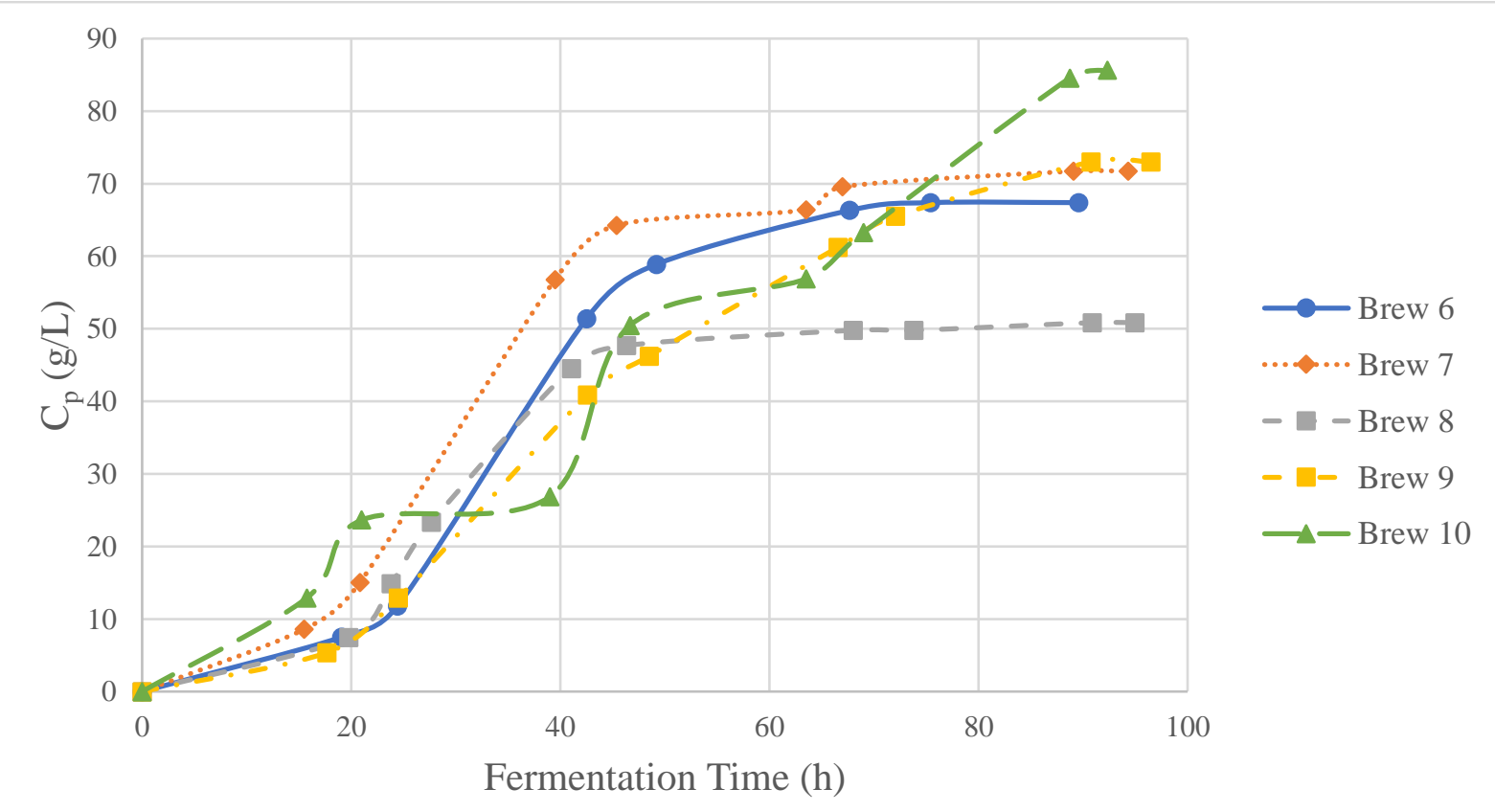

Figure 5: Ethanol concentration over time data obtained from Brews 6-10 in the Spring 2020 Unit Ops Lab II course. 


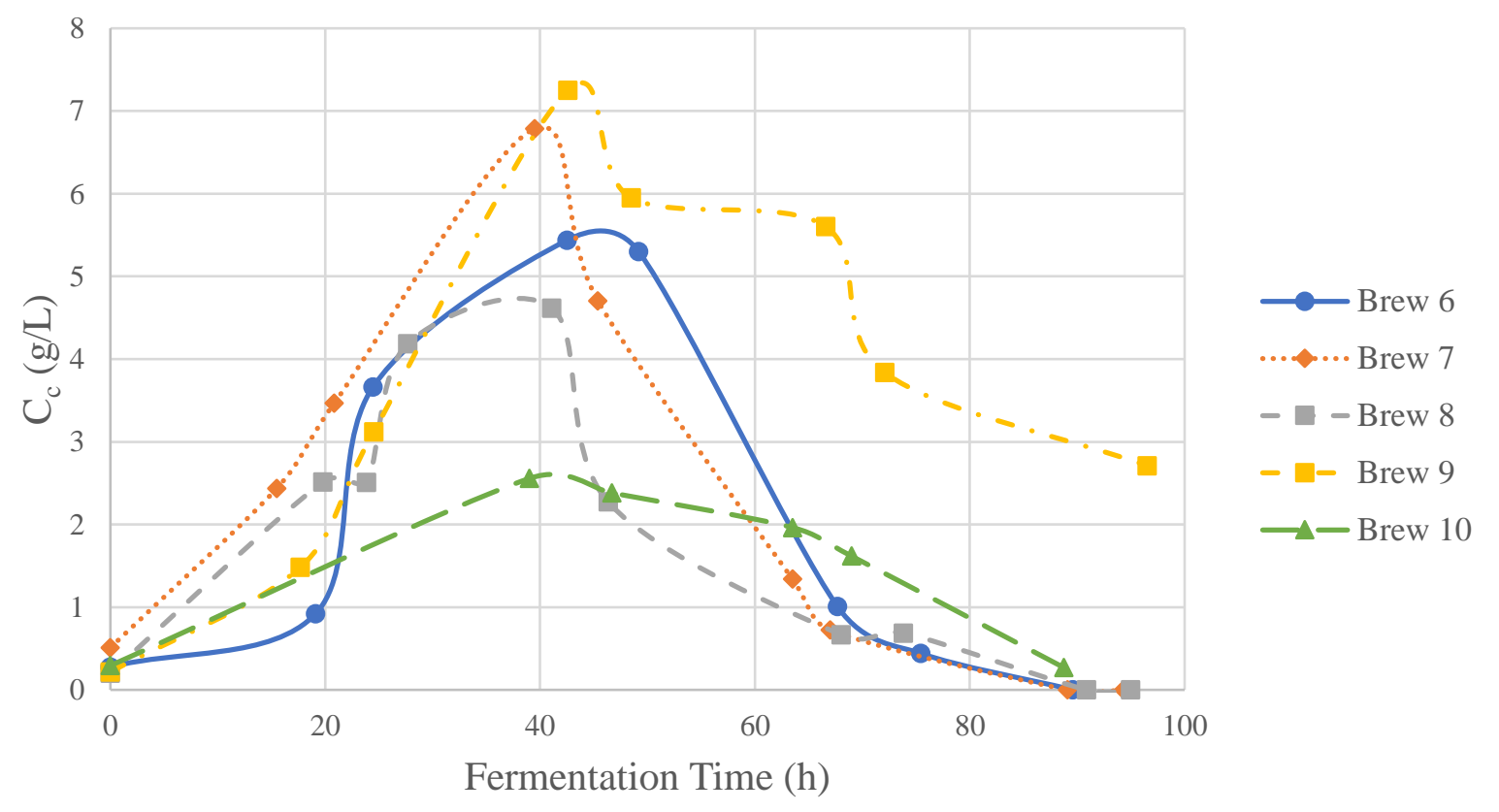

Figure 6: Yeast cell concentration over time data obtained from Brews 6-10 in the Spring 2020 Unit Ops Lab II course.

The conversion results from Table 3 were not surprising, except the $86.27 \%$ conversion from Brew 10. It was expected that Brew 7 would have a higher conversion than Brew 6, because there are more yeast cells available to convert the glucose to ethanol or to energy for cell maintenance. It was expected that Brew 8 and 9 would have similar conversion as Brew 6; with the initial concentration of yeast being the same, similar amounts of glucose would be consumed throughout the fermentation. It was not expected that Brew 10 would have such a high conversion when compared to Brew 6. It was suspected that errors were made when sampling, which was supported by the oscillations in Figures 4 and 5 and by the omission of some absorbance values due to not following the proper spectrophotometry procedures. Brew 10 should have a lower conversion since the yeast cells are not able to grow as easily in the filtered environment, because the filtered wort lacked nutrients needed by yeast cells for transport of sugars through the cell membrane ${ }^{18}$. With 
the yeast cells not able to grow as quickly, less glucose was consumed for maintenance and less ethanol was produced since there were fewer yeast cells to convert the glucose.

The yields from Table 3 were also all predicted except for Brews 7 and 10. Brew 7 was expected to have a lower yield than Brew 6 since more yeast cells would need more glucose for maintenance. A higher maintenance term meant that more glucose was being consumed, but it is not all going to ethanol since it is being converted to energy. Brew 8 was expected to have a lower yield. The yeast consumed roughly the same amount of glucose for maintenance as in Brew 6; however, since there is a lower concentration of glucose available, due to less dextrin breaking down into fermentable sugars, less ethanol will be able to be produced. The opposite case explains why the high yield was expected Brew 9. The higher concentration of glucose allowed the yeast to produce more ethanol. Brew 10 was not expected to have a higher yield Brew 6. With the yeast cells not being able to grow as quickly, it was expected that less ethanol would be produced, lowering the yield.

The shapes of the yeast cell concentration curves in Figure 6 were predicted for Brews 7, 8, and 10; however, the shape of the yeast cell concentration curve for Brew 9 was not expected. For Brew 7, there was an initially higher yeast cell concentration, which resulted in a higher peak concentration of yeast cells. The peak was observed at a slightly shorter fermentation time, which was explained by the yeast cells struggling to maintain homeostasis in the higher ethanol concentration. For Brew 8, the lower yeast cell concentration was expected since there was less glucose for the yeast cells to maintain homeostasis. The shape of the yeast cell concentration curve for Brew 10 matched the results obtained by Schisler et. al. ${ }^{18}$ from the fermentation of a filtered wort. The yeast cells were unable to grow as quickly in the filtered wort, reducing the amount of ethanol produced. The lower ethanol concentration reduced the death rate of the yeast cells, 
resulting in the observed trend in Figure 6. However, it is possible that the yeast cell concentration curve for Brew 10 was erroneous. The first two absorbance values after the initial sample were omitted; without the omitted values, it is uncertain how the yeast cells initially grew.

The death phase of the Brew 9 yeast cell concentration profile was not expected. It was predicted that the yeast concentration would grow larger than Brew 6 since there was more glucose available; however, the concentration profile not decreasing to zero was unexpected. This unexpected shape could be explained by two factors: bacteria contamination or an inadequate yeast cell concentration calibration curve. If bacteria were allowed to enter the fermenter jar, the bacteria would compete with the yeast cells for the available glucose, reducing the yield ${ }^{19}$. A growing bacteria culture could have the potential to absorb the light emitted from the spectrophotometer. This light absorbed from the would raise the absorbance of the sample, resulting in a higher reported yeast cell concentration. An inadequate yeast cell concentration calibration curve could be explained by the higher amount of DME used and the larger volume of wort to ferment. A new yeast cell concentration calibration curve needed to be made for Brew 8 due to the larger volume of wort left, resulting in a lighter color of the beer. The $25 \%$ more DME resulted in a darker color for the beer but there was also a larger volume of wort. These color-changing parameters may not have offset each other enough and it was possible that a new yeast cell concentration calibration curve needed to be made in order to accurately determine the amount of yeast present in Brew 9.

After calculating the percent conversion, yield, and experimental concentration profiles, the brews were modeled in Polymath by combining Equations 1-6 into mass balances of glucose, ethanol, and yeast cells. The yield coefficient of cells to substrate and the yield coefficient of product to cells were calculated for each of the five brews and the constants discussed in the Theory ${ }^{13}$ were used in the kinetic models for $\mathrm{C}_{\mathrm{c}}, \mathrm{C}_{\mathrm{s}}, \mathrm{C}_{\mathrm{p}}$. The maximum specific growth reaction rate, $\mu_{\max }$, was 
manually adjusted until the theoretical $C_{s}$ and the $C_{p}$ matched the experimental values at the time that the $\mathrm{C}_{c}$ was at its maximum value. Table 4 summarizes the $\mu_{\max }$ values calculated and the equations and values used in Polymath can be found in Appendix B: Sample Calculations.

Table 4: The $\mu_{\max }$ values of the

Unit Ops Lab II brews.

\begin{tabular}{|c|c|}
\hline Brew & $\begin{array}{c}\boldsymbol{\mu}_{\text {max }} \text { from } \\
\text { Polymath }\left(\mathbf{h}^{-1}\right)\end{array}$ \\
\hline Brew 6 & 0.085 \\
\hline Brew 7 & 0.082 \\
\hline Brew 8 & 0.0915 \\
\hline Brew 9 & 0.097 \\
\hline Brew 10 & 0.0655 \\
\hline
\end{tabular}

When solving for the $\mu_{\max }$ values, the theoretical $C_{s}$ and $C_{p}$ values matched the experimental values within $2.5 \%$, but the theoretical $\mathrm{C}_{\mathrm{c}}$ values were always between $13-16 \%$ lower. To match the theoretical $C_{c}$ values to the experimental $C_{c}$ values, the $k_{d}, m, K_{s}, n$, and $C_{p}{ }^{*}$ values could all be adjusted. Changing these values, though, would also change the theoretical $C_{s}$ and $C_{p}$ values, requiring the $\mu_{\max }$ values to be recalculated as well. To find the actual values for the constants, calculations would be iterated until the theoretical concentrations matched the experimental values. However, since there are many adjustable parameters and only a few data points, there likely exist many sets of parameters that fit the experimental data. Since the theoretical concentrations did not align with the experimental concentrations, the constants from Fogler were determined to be incorrect for these systems.

\section{Error Analysis}

Samples were taken two times a day during the fermentation, however, only one sample was taken each time. Because only one sample was taken, error bars could not be put on the concentration 
profiles. If multiple samples were taken each time and the samples were drawn from different parts of the fermenter, then a more accurate concentration profile could be made. By sampling from different parts of the fermenter and averaging the results, the overall system would be represented instead of only a portion. Taking multiple samples would also allow error bars to be drawn on the concentration profiles, providing a visual representation of how much variation was present throughout the fermentation.

The refractometer used to take samples has a \pm 0.2 Brix $\%$ error. Table 5 shows the percent errors for the calculated values due to the error in the refractometer.

Table 5: Maximum possible percent error of Brew 6 caused from the refractometer.

\begin{tabular}{|c|c|}
\hline Term & Percent Error \\
\hline SG & 0.196 \\
\hline $\mathrm{C}_{\mathrm{s}}$ & 8.108 \\
\hline $\mathrm{C}_{\mathrm{p}}$ & 28.495 \\
\hline Percent Conversion & 28.951 \\
\hline Yield & 0.501 \\
\hline
\end{tabular}

While the $C_{p}$ and percent conversion maximum percent error is high, this was only for the first sample when product concentration is low. When looking at the percent error of $\mathrm{C}_{\mathrm{p}}$ and percent conversion at the end of fermentation, the error was approximately $3.2 \%$ for both.

The fermenters were all placed in a temperature-controlled room and the temperature was maintained near $20^{\circ} \mathrm{C}$, the optimum temperature for ale yeasts ${ }^{15}$. If the temperature were higher, the yeast cells would be expected to grow more quickly. If bacteria were to enter the fermenter, they would compete with the yeast cells for the glucose. Common contaminants produce lactic and acetic acid, which lower $\mathrm{pH}$ and are toxic to yeast cells ${ }^{19}$. If contamination were present, the 
glucose concentration would continue to decrease as the bacteria and yeast are both consuming it; however, the yeast cell concentration would start to drop as the by-products from the bacterial cell respiration would inhibit yeast growth. If a tasting component were added to this lab, bacterial contamination would significantly affect taste profiles.

\section{Recommendations from Unit Ops Lab II Students}

From the four groups that performed the Fermentation Experiment during the Spring 2020 Unit Ops Lab II course, there were six recommendations presented in order to improve the experiment.

1. "One recommendation for improvement to the lab would be to eliminate estimating the density from a chart and using one standard equation to determine the density or finding a new way to determine the density of the solution in the lab. A different way to directly determine the specific gravity would be to purchase a hydrometer..."

The standardization of the equations to calculate SG was implemented into the recommended fermentation experiment. Using the Brucrafter calculator ${ }^{17}$ to determine the SG of the fermenting beer would create consistent ranges of values throughout the groups, allowing them to compare with each other more easily. More equations were added to procedure to clearly define all equations. The main equations needed were those from the UCI Microbiology Lab ${ }^{12}$ to calculate the $\mathrm{ABW}$ of the beer. The addition of a hydrometer was not included in the recommended procedure. The dimensions of the provided 1-gallon glass fermenter jars would not accommodate a hydrometer. The transfer of wort into a new container to sample with a hydrometer was also not recommended because of the risk of contamination when transferring the sample back into the fermenter. The volume needed to sample with the hydrometer is also too large to not return to the fermenter. After four instances of not returning the sample, the volume of beer would drop by 
approximately one third of the initial amount. Continued sampling would drastically affect the fermentation by removing glucose and yeast.

2. "One recommendation for improvement for the lab would be to move the Wednesday fermentation lab to a Monday..."

There was only one 3.5-quart pot available to prepare the wort in during the Spring 2020 Unit Ops Lab II. Purchasing another container to boil the wort would allow multiple groups to ferment on the same day. A problem may arise in years where there are more than 10 lab groups in the Unit Ops Lab courses. For the Fall 2019 and Spring 2020 courses, there were 10 groups total, with five meeting on Monday or Wednesday and the other five meeting on Tuesday. When there are more than 10 groups throughout the courses, all three days will be used to run the experiments. This may cause a space issue. While conducting the fermentation experiment earlier in the week is advised, it may be difficult to implement.

3. "One recommendation for this lab would be to increase the amount of water added to the fermentation samples for the spectrophotometry portion of the experiment."

To make the calibration curves more accurate, the majority of the samples taken should fall in the middle of the calibration curve ${ }^{20}$. The recommended procedure was updated to add $15 \mathrm{~mL}$ of DI water to dilute for spectrophotometry instead of the $7 \mathrm{~mL}$ used in the Spring 2020 Unit Ops Lab II course. Adding $15 \mathrm{~mL}$ of DI water will drive absorbance reading below 1.000 and the calibration curve should be more linear, also improving accuracy. New calibration curves following the 15 $\mathrm{mL}$ DI water dilution method should be created and provided to future students.

4. "Another recommendation to increase accuracy of the samples taken throughout the fermentation would be to ensure proper mixing of the beer before taking the sample." 
This recommendation was rejected for two reasons: (1) possibility of harming the yeast cells and (2) providing erroneous yeast cell concentrations when tested by spectrophotometry. Excessive stirring of yeast cells can lead to yeast cell disentegration ${ }^{21}$. The decrease of living yeast cells would provide inconsistent results in the concentration profiles throughout the experiment. Mixing of the beer before the sampling would also cause all of the undissolved solids that had settled at the bottom of the fermenter jar to be dispersed throughout the beer. The extra undissolved solids, consisting of dead yeast cells and undissolved malt, would absorb more light during spectrophotometry, resulting in an incorrect measurement for yeast cell concentration.

5. "The team also recommends that a sample spout be added to the fermenter."

A fermenter with a spout to take samples would significantly decrease the possibility of contamination. The spout would have to be about an inch from the bottom of the fermenter, though, to prevent the settled, undissolved solids from coming through the sample spout. Many homebrew stores offer such fermentation vessels for a relatively low price. If contamination concerns persist through more runs of the Fermentation Experiment, then this recommendation could be used.

6. "Another recommendation to this lab would be to investigate other factors that may have an effect on fermentation. One example would be to compare the performance of different strains of yeast...Heating the mash to different temperatures would also be something that could be investigated."

The effects of using a different yeast and DME were added to the recommended procedure. Different strains of yeast exhibit different fermenting rates as well as different maintenance requirements, which alter all of the concentration profiles monitored throughout the experiment. Using a different DME would affect the amount and profile of fermentable sugars available for the 
yeast cells. The option of changing the heating temperature of the wort, however, was not included in the recommended procedure. Lowering the temperature would result in the wort not boiling, which would not guarantee sterilization of the water and DME and could lead to less fermentable sugars available to the yeast. Raising the heating temperature of the wort would require the temperature of the wort to exceed $100{ }^{\circ} \mathrm{C}$, which would require a pressure vessel.

\section{E. Student Response Survey}

A student response survey was distributed to the students that completed the fermentation experiment and 11 of the 16 students completed the survey. The survey questions and results can be seen in Table 6.

Table 6: Results from the Student Response Survey.

\begin{tabular}{|l|c|}
\hline Question & $\begin{array}{c}\text { Average Score } \\
\text { (1=Strongly Disagree, } \\
\text { 5=Strongly Agree) }\end{array}$ \\
\hline $\begin{array}{l}\text { 1.) The purpose of the experiment was well defined and I } \\
\text { understood why I was completing the lab. }\end{array}$ & 4 \\
\hline $\begin{array}{l}\text { 2.) The Lab Requirements were well laid out and I understood } \\
\text { what I needed to discuss in the Results section. }\end{array}$ & 3.73 \\
\hline $\begin{array}{l}\text { 3.) I felt lost when trying to complete the calculations. I wish } \\
\text { there was more structure and equations given. }\end{array}$ & 3.73 \\
\hline $\begin{array}{l}\text { 4.) I feel like I was able to draw appropriate conclusions from } \\
\text { the data collected and make comparisons to expected outcomes. }\end{array}$ & 4.1 \\
\hline $\begin{array}{l}\text { 5.) I think the Lab Requirements are better defined in the new } \\
\text { procedure. I am aware of what needs to be completed and } \\
\text { calculated. }\end{array}$ & 4 \\
\hline $\begin{array}{l}\text { 6.) I think that the Theory in the new procedure offers more } \\
\text { direction and a better understanding of how to calculate the } \\
\text { needed results. }\end{array}$ & 4.54 \\
\hline
\end{tabular}

From the student responses, the recommended procedure properly explains what needs to be calculated and how to perform the calculations. The students also agree that they were able to draw conclusions as to why the different brews behaved like they did. All student groups received a B- 
or above on their written group reports. The passing grade along with the students agreeing to questions 1 and 4 shows that the learning objectives of the fermentation were met. 


\section{CONCLUSIONS AND RECOMMENDATIONS}

The distillery and brewery industries are quickly growing in Kentucky. To provide University of Louisville chemical engineering students with the knowledge needed to enter these industries, a fermentation experiment should be added to the Unit Ops Lab II course. This experiment will reinforce the theory of bioreaction kinetics and allow students to perform similar analysis and calculations used in these industries.

Four groups of students successfully completed the fermentation experiment during the Spring 2020 Unit Ops Lab II course. The groups met all of the lab requirements and successfully analyzed the experimental data to determine concentration profiles and reaction kinetics. The results produced from the brews throughout the course mostly matched expected results, with discrepancies being attributed to potential bacterial contamination, improper sampling procedures, and inadequate calibration curves. These factors that caused the unexpected results can be corrected with more attention to the sampling procedures and with the implementation of more calibration curves.

If the fermentation experiment is added to the Unit Ops Lab II course, the TAs should perform the experiment together before the Spring labs begin to gain experience with the sampling procedures and to obtain more data for the standard brew that student groups can use as control experiments. The TAs can perform the experiment after the Fall labs end, during Winter break, or during the Introduction week to the Unit Ops Lab II course. The TAs should also prepare new yeast cell concentration calibration curves following the spectrophotometry procedure found within the recommended fermentation experiment. 
Another pot to boil the wort should be purchased. Having more than one pot would allow multiple groups to perform the fermentation experiment on the same day. Having the option of performing multiple fermentation experiments on the same day allows the fermentation experiment to be used as a backup if another experiment's equipment is not functioning properly. Another scale should also be purchased or brought out of storage. This scale does not need to read to four decimal points (i.e. with 0.1 milligram precision) like the current one does. One decimal point accuracy would suffice. This new scale would be for measuring the DME. The scale used to measure the yeast has a maximum tolerance of $250 \mathrm{~g}$ while $269 \mathrm{~g}$ of DME is needed for the base fermentation. Having another scale would eliminate the need for two separate scale in two rooms.

It is recommended that the use of Polymath should be further studied. An experiment could be conducted that measures the change in concentration of glucose and cells every hour for four hours. This data would allow the Hanes-Woolf form of the Monod equation to be used ${ }^{13}$. From the HanesWoolf equation, $\mathrm{K}_{\mathrm{s}}$ and $\mu_{\max }$ can be determined experimentally. Once these two constants are known, Polymath could be used to determine $\mathrm{k}_{\mathrm{d}}, \mathrm{m}, \mathrm{n}$, and $\mathrm{C}_{\mathrm{p}}{ }^{*}$ by iteratively changing the values of those constants until the theoretical concentrations of substrate, product, and cells match with the experimental concentrations.

A future Master of Engineering student could explore the use of high-performance liquid chromatography (HPLC). Using HPLC to determine the concentrations of each fermentable sugar and ethanol was a goal of this experiment but it was not accomplished. The samples of Brews 6, 7, 9, and 10 were tested along with one set of experimental standards using HPLC, however, the results were never analyzed by the students. The results are stored on the computer in the A.R.M. Lab in Lutz Hall. Once enough experimental standards for HPLC have been tested to allow for a wide concentration range, the Master's student could then prepare more brews, sample them as 
described in the recommended procedure, and sample them with HPLC to compare the results. HPLC analysis could then be added to the fermentation experiment, providing undergraduate students with hands-on experience with chromatography, and the validity of using a refractometer could be established. 


\section{REFERENCES}

1. State Craft Beer Sales \& Production Statistics, 2018, 2018. Brewers Association. https://www.brewersassociation.org/statistics-and-data/state-craft-beer-stats/ (accessed April 9, 2020).

2. Projections look bright for Kentucky breweries in 2017 and beyond, 2017. Louisville Future. https://louisvillefuture.com/archived-news/projections-look-bright-forkentucky-breweries-in-2017-and-beyond/ (accessed April 9, 2020).

3. Loosemore, B. From 19 to 68 distilleries: How Kentucky bourbon has grown since 2009. The Courier Journal [Online], Feb 6, 2019, https://www.courierjournal.com/story/life/food/spirits/bourbon/2019/02/06/how-bourbon-spiritsindustries-impact-kentucky-economy/2778376002/ (accessed April 9, 2020).

4. Patton, J. After a decade of 'explosive growth' for Kentucky distilleries, what's next? The Lexington Herald Leader [Online], Feb 6, 2019, https://www.kentucky.com/lexgoeat/bourbon/article225559280.html (accessed April 9, 2020).

5. Daroch, M.; Geng, S.; Wang, G. Recent advances in liquid biofuel production from algal feedstocks. Applied Energy. 2013, 102, 1371-1381.

6. Production of pharmaceutical compounds through microbial fermentation. Manufacturing Chemist [Online], Jun 8, 2011, https://www.manufacturingchemist.com/news/article_page/Production_of_pharmaceu tical_compounds_through_microbial_fermentation/61614 (accessed April 22, 2020).

7. Gerstle, J.G. CHE 485 - Unit Operations Laboratory I Syllabus; University of Louisville: Louisville, KY, 2019.

8. Gerstle, J.G. CHE 485 - Unit Operations Lab I Lab Procedures; University of Louisville: Louisville, KY, 2019.

9. Gerstle, J.G. CHE 486 - Unit Operations Lab II Lab Procedures; University of Louisville: Louisville, KY, 2020.

10. Criteria for Accrediting Engineering Technology Programs, 2019-2020, 2018. ABET. https://www.abet.org/accreditation/accreditation-criteria/criteria-for-accreditingengineering-technology-programs-2019-2020/\#GC2 (accessed April 9, 2020).

11. Sato, B.K.; Alam, U.; Dacanay, S.J.; Lee, A.K.; Shaffer, J.F. Brewing for Students: An Inquiry-Based Microbiology Lab. Journal of Microbiology \& Biology Education. 2015, 16, 223-229.

12. Sato, B.K.; Alam, U.; Dacanay, S.J.; Lee, A.K.; Shaffer, J.F. Supplemental Material for Brewing for Students: An Inquiry-Based Microbiology Lab. Journal of Microbiology \& Biology Education. 2015, 16, 223-229.

13. Fogler, H.S. Elements of Chemical Reaction Engineering, $5^{\text {th }}$ ed.; Pearson: Kendallville, IN, 2016; pp 364-381.

14. Aquilla, T. The Biochemistry of Yeast - Aerobic Fermentation. MoreBeer! [Online], Jul 25, 2013, https://www.morebeer.com/articles/how_yeast_use_oxygen (accessed April 22, 2020). 
15. Stewart, G.G. The Horace Brown Medal Lecture: Forty Years of Brewing Research. Journal of the Institute of Brewing. 2009, 115, 3-29.

16. BRIX - Sugar Determination By Density and Refractometry, 2014. Fisher Scientific. https://beta-

static.fishersci.com/content/dam/fishersci/en_US/documents/programs/scientific/tech nical-documents/technical-bulletins/mettler-toledo-brix-sugar-determinationtechinical-bulletin.pdf (accessed April 22, 2020).

17. Brix to SG Conversion (Calculators, Formula, Table, Alcohol Correction), 2019. Brucrafter.com. http://brucrafter.com/convert-brix-to-sg/ (accessed April 8, 2020).

18. Schisler, D.O.; Ruocco, J.J.; Mabee, M.S. Wort Trub Content and Its Effects on Fermentation and Beer Flavor. American Society of Brewing Chemists, Inc. 1982, 40, 57-61.

19. Narendranath, N.V. Bacterial contamination and control in ethanol production. In The Alcohol Textbook, 4th ed.; Jacques, K.A.; Lyons, T.P.; Kelsall, D.R., Eds.; Nottingham University Press: Nottingham, UK, 2003; pp 287-298.

20. Preparation of Calibration Curves, A Guide to Best Practice, 2003. LGC. https://biosearch-cdn.azureedge.net/assetsv6/Calibration-curve-guide.pdf (accessed April 8, 2020).

21. Kwade, A.; Schwedes, J. Breaking characteristics of different materials and their effect on stress intensity and stress number in stirred media mills. Powder Technology. 2002, 122, 109-121.

22. Density of aqueous solutions of organic substances as sugars and alcohols, 2017. The Engineering Toolbox. https://www.engineeringtoolbox.com/density-aqueoussolution-organic-sugar-alcohol-concentration-d_1954.html (accessed April 8, 2020). 


\section{APPENDICES}

Appendix A: Raw Data

Table 7: Wort preparation for Brews 1-10.

\begin{tabular}{|c|c|c|c|c|c|}
\hline Brew & DME $(\mathbf{g})$ & Hops $(\mathbf{g})$ & Yeast $(\mathbf{g})$ & Boil Time (h) & Final Volume (L) \\
\hline 1 & 269.9 & 6.0 & 1.1 & 1.0 & - \\
\hline 2 & 273.2 & 5.5 & 0.3 & 1.0 & 1.242 \\
\hline 3 & 271.0 & 5.6 & 0.3 & 1.0 & 1.183 \\
\hline 4 & 270.1 & 5.8 & 0.3 & 1.0 & 1.180 \\
\hline 5 & 270.3 & 5.6 & 0.3 & 1.0 & 1.205 \\
\hline 6 & 269.1 & - & 0.3111 & 1.0 & 1.124 \\
\hline 7 & 269.3 & - & 0.6189 & 1.0 & 1.210 \\
\hline 8 & 269.1 & - & 0.3115 & 0.5 & 1.538 \\
\hline 9 & 336.5 & - & 0.3007 & 1.0 & 1.400 \\
\hline 10 & 269.3 & - & 0.3122 & 1.0 & 1.065 \\
\hline
\end{tabular}

Table 8: Sampling data for Brew 1.

\begin{tabular}{|c|c|}
\hline Fermentation Time (h) & Brix \% \\
\hline 0.00 & 21.3 \\
\hline 23.08 & 19.4 \\
\hline 47.83 & 11.6 \\
\hline 75.92 & 10.9 \\
\hline 99.17 & 10.7 \\
\hline 122.92 & 10.6 \\
\hline 143.92 & 10.6 \\
\hline
\end{tabular}

Table 9: Sampling data for Brew 2.

\begin{tabular}{|c|c|}
\hline Fermentation Time (h) & Brix \% \\
\hline 0.00 & 20.0 \\
\hline 18.78 & 19.8 \\
\hline 20.78 & 19.2 \\
\hline 26.53 & 18.8 \\
\hline 47.20 & 12.8 \\
\hline 49.28 & 12.2 \\
\hline 68.78 & 11.3 \\
\hline 70.78 & 11.1 \\
\hline 73.70 & 11.0 \\
\hline 89.87 & 11.0 \\
\hline 97.20 & 11.0 \\
\hline & \\
\hline
\end{tabular}


Table 10: Sampling data for

Brew 3.

\begin{tabular}{|c|c|}
\hline $\begin{array}{c}\text { Fermentation Time } \\
(\mathbf{h})\end{array}$ & $\begin{array}{c}\text { Brix } \\
\text { \% }\end{array}$ \\
\hline 0.00 & 20.2 \\
\hline 5.83 & 20.2 \\
\hline 26.50 & 19.2 \\
\hline 28.67 & 19.0 \\
\hline 48.17 & 13.0 \\
\hline 50.17 & 12.5 \\
\hline 53.07 & 12.2 \\
\hline 69.25 & 11.6 \\
\hline 76.57 & 11.4 \\
\hline 92.00 & 11.1 \\
\hline 99.13 & 11.1 \\
\hline 124.07 & 11.1 \\
\hline
\end{tabular}

Table 11: Sampling data for Brew 4.

\begin{tabular}{|c|c|}
\hline $\begin{array}{c}\text { Fermentation Time } \\
\text { (h) }\end{array}$ & $\begin{array}{c}\text { Brix } \\
\text { \% }\end{array}$ \\
\hline 0.00 & 20.3 \\
\hline 19.85 & 20.1 \\
\hline 21.85 & 20.0 \\
\hline 24.72 & 19.3 \\
\hline 40.92 & 13.4 \\
\hline 48.23 & 12.4 \\
\hline 63.67 & 11.8 \\
\hline 70.80 & 11.6 \\
\hline 95.73 & 11.3 \\
\hline 113.05 & 11.1 \\
\hline 118.32 & 11.1 \\
\hline 141.27 & 11.1 \\
\hline
\end{tabular}

Table 12: Sampling data for Brew 5.

\begin{tabular}{|c|c|}
\hline $\begin{array}{c}\text { Fermentation Time } \\
\text { (h) }\end{array}$ & $\begin{array}{c}\text { Brix } \\
\text { \% }\end{array}$ \\
\hline 0.00 & 19.8 \\
\hline 3.27 & 19.8 \\
\hline 19.50 & 18.8 \\
\hline 26.80 & 18.4 \\
\hline 42.23 & 13.4 \\
\hline 49.45 & 12.2 \\
\hline 74.28 & 11.1 \\
\hline 91.63 & 11.0 \\
\hline 96.87 & 10.9 \\
\hline 119.83 & 10.9 \\
\hline
\end{tabular}

Table 13: Sampling data for Brew 6.

\begin{tabular}{|c|c|c|}
\hline $\begin{array}{c}\text { Fermentation Time } \\
(\mathbf{h})\end{array}$ & Abs & $\begin{array}{c}\text { Brix } \\
\text { \% }\end{array}$ \\
\hline 0.00 & - & 20.7 \\
\hline 19.10 & 1.875 & 20.0 \\
\hline 24.43 & 2.529 & 19.4 \\
\hline 42.52 & 2.953 & 14.1 \\
\hline 49.18 & 2.920 & 13.0 \\
\hline 67.68 & 1.896 & 12.0 \\
\hline 75.43 & 1.761 & 11.9 \\
\hline 89.60 & 1.523 & 11.9 \\
\hline
\end{tabular}


Table 14: Sampling data for Brew 7.

\begin{tabular}{|c|c|c|}
\hline $\begin{array}{c}\text { Fermentation Time } \\
(\mathbf{h})\end{array}$ & Abs & $\begin{array}{c}\text { Brix } \\
\text { \% }\end{array}$ \\
\hline 0.00 & - & 21.1 \\
\hline 15.50 & 1.617 & 20.3 \\
\hline 20.83 & 1.816 & 19.4 \\
\hline 39.50 & 2.459 & 13.8 \\
\hline 45.38 & 2.056 & 12.7 \\
\hline 63.50 & 1.404 & 12.4 \\
\hline 67.00 & 1.285 & 12.0 \\
\hline 89.08 & 1.074 & 11.7 \\
\hline 94.33 & 1.151 & 11.7 \\
\hline & & \\
\hline
\end{tabular}

Table 16: Sampling data for Brew 9.

\begin{tabular}{|c|c|c|}
\hline $\begin{array}{c}\text { Fermentation Time } \\
(\mathbf{h})\end{array}$ & Abs & $\begin{array}{c}\text { Brix } \\
\text { \% }\end{array}$ \\
\hline 0.00 & - & 22.4 \\
\hline 17.68 & 1.432 & 22.0 \\
\hline 24.50 & 1.749 & 21.1 \\
\hline 42.58 & 2.549 & 17.4 \\
\hline 48.50 & 2.297 & 16.6 \\
\hline 66.58 & 2.230 & 14.6 \\
\hline 72.08 & 1.888 & 14.0 \\
\hline 90.77 & - & 13.0 \\
\hline 96.50 & 1.670 & 13.0 \\
\hline
\end{tabular}

Table 15: Sampling data for Brew 8.

\begin{tabular}{|c|c|c|}
\hline $\begin{array}{c}\text { Fermentation Time } \\
(\mathbf{h})\end{array}$ & Abs & $\begin{array}{c}\text { Brix } \\
\text { \% }\end{array}$ \\
\hline 0.00 & - & 16.0 \\
\hline 19.77 & 1.277 & 15.2 \\
\hline 23.83 & 1.276 & 14.2 \\
\hline 27.68 & 1.587 & 13.0 \\
\hline 41.08 & 1.667 & 10.0 \\
\hline 46.33 & 1.232 & 9.4 \\
\hline 68.02 & 0.934 & 9.2 \\
\hline 73.82 & 0.938 & 9.2 \\
\hline 90.87 & 0.760 & 9.0 \\
\hline 94.97 & 0.774 & 9.0 \\
\hline
\end{tabular}

Table 17: Sampling data for Brew 10.

\begin{tabular}{|c|c|c|}
\hline $\begin{array}{c}\text { Fermentation Time } \\
(\mathbf{h})\end{array}$ & Abs & $\begin{array}{c}\text { Brix } \\
\mathbf{\%}\end{array}$ \\
\hline 0.00 & - & 21.8 \\
\hline 15.75 & - & 20.4 \\
\hline 21.00 & - & 19.0 \\
\hline 39.00 & 1.64 & 18.6 \\
\hline 46.67 & 1.606 & 15.4 \\
\hline 63.50 & 1.525 & 14.6 \\
\hline 69.00 & 1.458 & 13.6 \\
\hline 88.75 & 1.197 & 10.6 \\
\hline 92.33 & - & 10.4 \\
\hline
\end{tabular}


Appendix B: Sample Calculations

The sample calculations will follow the data gathered from the Standard Brew, performed during the Spring 2020 Unit Ops Lab II course.

\section{Brix \% to SG}

Initial Brix $\%=20.7 \%$

From Equation 7:

$$
S G=\frac{\text { Brix } \%}{258.6-227.1\left(\frac{\text { Brix } \%}{258.3}\right)}+1=\frac{20.7}{258.6-227.1\left(\frac{20.7}{258.3}\right)}+1=1.086
$$

The other SG conversions were done using the Brucrafter Brix-to-SG calculator ${ }^{12}$

\section{$\underline{\text { SG to } \mathrm{C}_{S}}$}

From Engineering Toolbox ${ }^{22}$, the density of different concentrations of glucose solutions was given.

Density $=1.0797$, Molarity $=1.199$

Density $=1.126$, Molarity $=1.873$

$$
\begin{gathered}
\text { Molarity }=\frac{1.086-1.0797}{1.126-1.0797}(1.873-1.199)+1.199=1.29 \frac{\text { mol Glucose }}{\text { L beer }} \\
1.29 \frac{\text { mol Glucose }}{\text { L beer }}\left(\frac{180.156 \text { g Glucose }}{1 \text { mol Glucose }}\right)=232.4 \frac{g \text { Glucose }}{\text { L beer }}
\end{gathered}
$$

\section{$\underline{\text { Absorbance to } \mathbf{C}_{\mathbf{c}}}$}

At Fermentation Time $=42.52 \mathrm{~h}$, Absorbance $=2.953$

From the Standard Brew yeast calibration curve in Appendix C:

$$
\text { Absorbance }=0.2386(\text { Concentration })+1.6556
$$

Therefore:

$$
\text { Concentration }=\frac{\text { Absorbance }-1.6556}{0.2386}=\frac{2.953-1.6556}{0.2386}=5.44 \frac{\mathrm{g} \text { Yeast }}{\mathrm{L} \text { beer }}
$$

\section{$\underline{\text { SG to } C_{p}}$}

Initial $\mathrm{SG}=1.086$, Final $\mathrm{SG}=1.023$

From Equation 9:

$$
\begin{aligned}
\text { Initial }^{\circ} \mathrm{P}= & -463.37+668.72(S G)-205.35(S G)^{2} \\
& =-463.37+668.72(1.086)-205.35(1.086)^{2}=20.67
\end{aligned}
$$


Final ${ }^{\circ} \mathrm{P}=5.83$

From Equation 10:

$$
\begin{gathered}
\text { Initial } R E=0.1808\left(\text { Initial } S G{ }^{\circ} P\right)+0.8192\left(\text { Sample } S G^{\circ} P\right) \\
=0.1808(20.67)+0.8192(20.67)=20.67
\end{gathered}
$$

Final RE $=8.51$

From Equation 8:

$$
\begin{gathered}
A B W=\frac{\left(\text { Initial } S G^{\circ} P\right)-R E}{2.0655-0.010665\left(\text { Initial } S G^{\circ} P\right)}=\frac{(20.67)-8.51}{2.0665-0.010665(20.67)} \\
=6.59 \frac{g \text { Ethanol }}{100 g \text { beer }} \\
6.59 \frac{g \text { Ethanol }}{100 \text { g beer }}\left(1.023 \frac{g \text { beer }}{m L \text { beer }}\right)\left(\frac{1000 \mathrm{~mL}}{1 L}\right)=67.42 \frac{g \text { Ethanol }}{L \text { beer }}
\end{gathered}
$$

\section{Percent Conversion and Yield}

$$
\begin{aligned}
& \% \text { Conversion }=\frac{\text { Initial moles Glucose }- \text { Final moles Glucose }}{\text { Initial moles Glucose }}(100 \%) \\
& =\frac{\left(232.4 \frac{g \text { Glucose }}{\text { L beer }}-65.37 \frac{g \text { Glucose }}{\text { Lbeer }}\right)\left(\frac{1 \text { mol Glucose }}{180.156 \text { Glucose }}\right)}{232.4 \frac{g \text { Glucose }}{\text { Lbeer }}\left(\frac{1 \text { mol Glucose }}{180.156 \text { glucose }}\right)}(100 \%) \\
& =71.87 \% \\
& \text { Yield }=\frac{\text { Final moles Ethanol }- \text { Initial Moles Ethanol }}{\text { Final moles Glucose }- \text { Initial Moles Glucose }} \\
& =\frac{\left(67.42 \frac{g \text { Ethanol }}{\text { Lbeer }}-0 \frac{\text { g Ethanol }}{\text { Lbeer }}\right)\left(\frac{1 \text { mol Ethanol }}{46.07 \text { Ethanol }}\right)}{\left(232.4 \frac{g \text { Glucose }}{L \text { beer }}-65.37 \frac{\text { g Glucose }}{L \text { beer }}\right)\left(\frac{1 \text { mol Glucose }}{180.156 \mathrm{~g} \text { Glucose }}\right)}=1.578
\end{aligned}
$$

\section{$\underline{Y_{\mathrm{c} / \mathrm{s}} \text { and } Y_{\mathrm{p} / \mathrm{c}}}$}

The Monod equation models growth during the exponential growth phase of the yeast cells, therefore the difference in product, call, and substrate concentrations will be calculated from the initial and the highest recorded $\mathrm{C}_{\mathrm{c}}$ value 
From Equation 5:

$$
Y_{c / s}=-\frac{\Delta C_{c}}{\Delta C_{s}}=-\frac{5.44 \frac{g \text { Yeast }}{\text { Lbeer }}-0.28 \frac{g \text { Yeast }}{\text { Lbeer }}}{105.10 \frac{g \text { Glucose }}{\text { Lbeer }}-232.4 \frac{g \text { Glucose }}{L \text { beer }}}=0.0405
$$

From Equation 6:

$$
Y_{p / c}=\frac{\Delta C_{p}}{\Delta C_{c}}=\frac{51.42 \frac{g \text { Ethanol }}{\text { Lbeer }}-0 \frac{\text { g Ethanol }}{\text { Lbeer }}}{5.44 \frac{g \text { Yeast }}{L \text { beer }}-0.28 \frac{\text { gYeast }}{\text { Lber }}}=9.96
$$

\section{Polymath Modeling}

The constants described in the Theory, along with the $Y_{c / s}$ and $Y_{p / c}$ terms and kinetic equations were combined in Polymath. The time started at 0 hours and ended at the time that the highest $\mathrm{C}_{\mathrm{c}}$ value was observed (42.52 h). The $\mu_{\max }$ term was adjusted until the $\mathrm{C}_{\mathrm{s}}$ and $\mathrm{C}_{\mathrm{p}}$ values closely matched the experimental

\begin{tabular}{|c|c|c|c|c|c|}
\hline & Variable & Initial value & Minimal value & Maximal value & Final value \\
\hline 1 & $\mathrm{Cc}$ & 0.28 & 0.28 & 4.608476 & 4.608476 \\
\hline 2 & Cp & 0 & 0 & 50.29419 & 50.29419 \\
\hline 3 & Cs & 232.53 & 105.6847 & 232.53 & 105.6847 \\
\hline 4 & kobs & 0.085 & 0.0567102 & 0.085 & 0.0567102 \\
\hline 5 & Ks & 1.7 & 1.7 & 1.7 & 1.7 \\
\hline 6 & $\mathrm{~m}$ & 0.03 & 0.03 & 0.03 & 0.03 \\
\hline 7 & rd & 0.0028 & 0.0028 & 0.0460848 & 0.0460848 \\
\hline 8 & $\mathrm{rg}$ & 0.0236273 & 0.0236273 & 0.2572101 & 0.2572101 \\
\hline 9 & $\mathrm{rsm}$ & 0.0084 & 0.0084 & 0.1382543 & 0.1382543 \\
\hline 10 & $\mathrm{t}$ & 0 & 0 & 42.52 & 42.52 \\
\hline 11 & umax & 0.085 & 0.085 & 0.085 & 0.085 \\
\hline 12 & Ypc & 9.96 & 9.96 & 9.96 & 9.96 \\
\hline 13 & YsC & 24.69136 & 24.69136 & 24.69136 & 24.69136 \\
\hline
\end{tabular}
values.

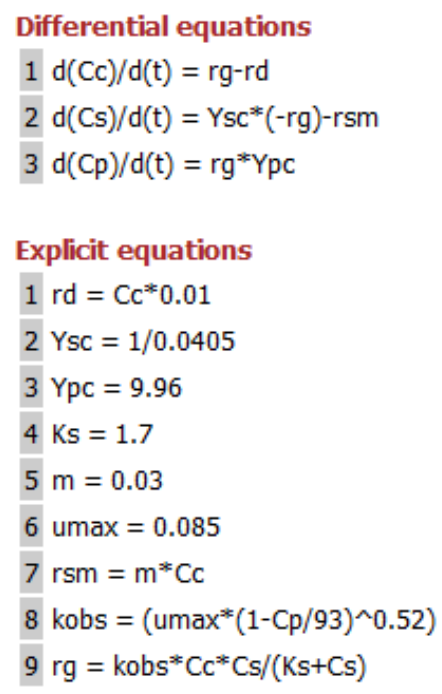


Appendix C: Yeast Cell Absorbance-Concentration Curves
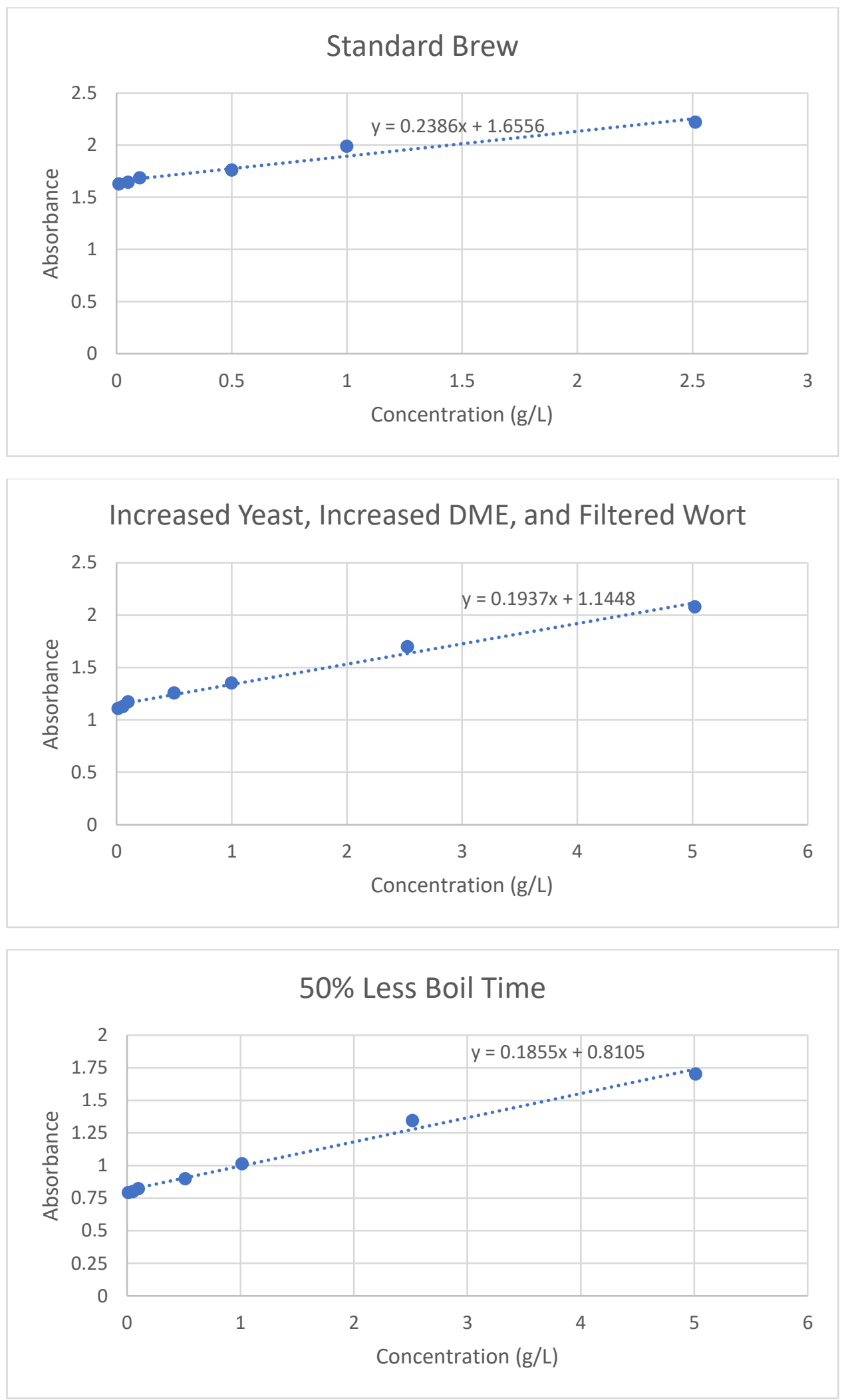
Appendix D: Recommended Procedure for Unit Ops Lab II

The font and style of the recommended procedure is the same that is used in the Unit Ops Lab II Lab Procedures ${ }^{9}$ so it can be added more easily.

\section{Fermentation}

\section{Learning Objectives}

In this lab you will study fermentation kinetics and measure the effects that different variables, located in the Lab Options, have on the overall kinetics of the reaction. The learning objectives of this experiment include:

- Fundamentals of bioreactions

- Use of a refractometer

- Calculating conversion and yield

\section{Lab Requirements (Experimental Objectives)}

The lab requirements must be completed and discussed/reported in the lab report. For the Fermentation lab, the requirements include:

- Calculate percent conversion and yield

- Compare concentration profiles and kinetics

- Model growth rate using the Monod equation

\section{Lab Options (Questions to be Answered)}

The Lab Options serve as a guide for deciding what question(s) your experiment will be answering. The options can be investigated by slightly altering the provided Experimental Procedure. The options for this lab include:

- Effects of initial mass of Dry Malt Extract (DME) - more or less Pale Ale DME added

- Effects of heating time - longer or shorter boiling time

- Effects of filtration - filtering the wort before fermentation starts

- Effects of initial yeast concentration - more or less yeast added

- Effects of different DME - using a different DME than Pale Ale DME

- Effects of different yeast types - using a different yeast than Nottingham Ale Yeast

- Others with TA approval

\section{Prelab Activity}

Before leaving on pre-lab day, each group must:

- Sketch P\&ID of equipment

- Familiarize yourself with sampling procedures

- Perform calibration of the refractometer

- Discuss Lab Requirements and Lab Options with the TA

- Discuss/determine modeling equations with the TA

- Complete the task list.

\section{Theory}

In a bioreaction, living cells use enzymes to convert specific reactants into products. The use of bioreactions to create commercial products, from food and medicines to polymers, has grown dramatically in past years. Advantages of bioreactions include relatively high yield, ambient-tomild reaction conditions, and stereospecific product formation. 
For this experiment, the cells are Baker's yeast cells (Saccharomyces cerevisiae), the substrate is glucose, and the product is ethanol. The glucose is provided by a DME of malted barley. The DME is boiled to breakdown the malt into glucose. The yeast cells use the glucose as an energy source as well as a reactant to produce ethanol. The ethanol, however, acts as an inhibitor to yeast growth as it creates a toxic environment, gradually slowing the fermentation process.

The growth rate of the cells throughout the fermentation process, taking into account the product inhibition, can be modeled by the empirical form of the Monod equation (Fogler, Equation 9-55):

$$
r_{g}=k_{o b s} \frac{\mu_{\max } C_{s} C_{c}}{K_{s}+C_{s}}
$$

where: $C_{c}=$ Cell concentration, $\mathrm{g} / \mathrm{L}$

$C_{s} \quad=$ Substrate concentration, $\mathrm{g} / \mathrm{L}$

$k_{\text {obs }}=$ Product inhibition factor, unitless

$K_{S}=$ Monod constant, $\mathrm{g} / \mathrm{L}$

$r_{g} \quad=$ Cell growth rate, $\mathrm{g} / \mathrm{L}-\mathrm{h}$

$\mu_{\max }=$ Maximum specific growth reaction rate, $\mathrm{h}^{-1}$

and the product inhibition factor can be obtained by (Fogler, Equation 9-56):

$$
k_{o b s}=\left(1-\frac{C_{p}}{C_{p}^{*}}\right)^{n}
$$

where: $\quad C_{p}=$ Product concentration, $\mathrm{g} / \mathrm{L}$

$C_{p}^{*} \quad=$ Product concentration at which all metabolism stops, $\mathrm{g} / \mathrm{L}$

$n=$ Empirical constant, unitless

The yeast cells will die naturally over time or when exposed to a toxic substance in high enough concentrations. Since the inhibition from the ethanol on the growth of yeast is accounted for in the Monod equation, only natural death of the yeast cells needs to be accounted for in the cell death rate. The cell death rate is (Fogler, Equation 9-59):

$$
r_{d}=k_{d} C_{c}
$$

where: $\quad k_{d}=$ Natural death rate constant, $\mathrm{h}^{-1}$

$r_{d}=$ Cell death rate, $\mathrm{g} / \mathrm{L}-\mathrm{h}$

When the cells use the substrate as an energy source instead of converting the substrate to products, the cells are maintaining homeostasis. The rate of substrate consumption for maintenance is (Fogler, Equation 9-67):

$$
r_{s m}=m C_{c}
$$

$$
\text { where: } \begin{aligned}
m & =\frac{\text { Mass of substrate consumed for maintenance }}{\text { Mass of cells } \cdot \text { time }}, \frac{g \text { substrate }}{g \text { cells } \cdot h} \\
r_{s m} & =\text { Rate of substrate consumption for maintenance, } \mathrm{g} / \mathrm{L}-\mathrm{h}
\end{aligned}
$$


In order to relate the amount of yeast cells produced to the amount of substrate consumed and amount of product produced, yield coefficients need to be calculated. The yield coefficient for cells and substrate is given by (Fogler, Equation 9-62):

$$
Y_{c / s}=-\frac{\Delta C_{c}}{\Delta C_{S}}
$$

where: $\quad Y_{c / s} \quad=$ Yield coefficient of cells to substrate, unitless

and the yield coefficient for product and cells is (Fogler, Equation 9-64):

$$
Y_{p / s}=\frac{\Delta C_{p}}{\Delta C_{c}}
$$

where: $\quad Y_{p / s} \quad=$ Yield coefficient of product to substrate, unitless

By combining the kinetic relationships with the yield coefficients, mass balance correlations are able to be formed. Integrating mass balance relationships using Polymath will result in concentration profiles for the respective chemical species. Comparison between the different concentration profiles and reaction rate profiles between the different conditions can then be carried out.

These theoretical profiles can also be compared to experimental values obtained from the samples taken throughout the fermentation process. In order to determine the amount of substrate present in the beer as it ferments, the Brix \% can be converted to specific gravity (SG), which can further be converted to a concentration. The initial Brix \% can be converted to an initial SG by (http://brucrafter.com/convert-brix-to-sg/):

$$
S G=\frac{\text { Brix } \%}{258.6-227.1\left(\frac{\text { Brix } \%}{258.2}\right)}+1
$$

where: Brix $\%=$ A measurement of Refractive Index, unitless

$S G \quad=$ Specific gravity of the beer, unitless

As ethanol is being produced, the Brix \% value will be affected by both the decrease in glucose and the increase in ethanol. Because of this, Equation 7 cannot be used to determine the SG of the beer after the initial sample. In order to determine the SG for the samples taken throughout the fermentation week, a Brix \% to SG conversion calculator is located on the website http://brucrafter.com/convert-brix-to-sg/.

In order to determine the amount of ethanol produced throughout the fermentation process, the alcohol by weight $(\mathrm{ABW})$ can be approximated by (Sato, Equation 3):

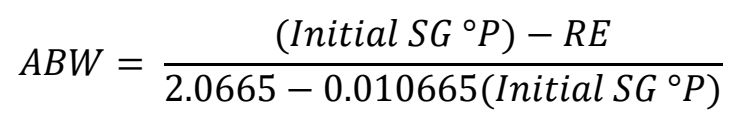


where: $A B W=$ Alcohol by weight, $\mathrm{g}$ ethanol $/ 100 \mathrm{~g}$ beer

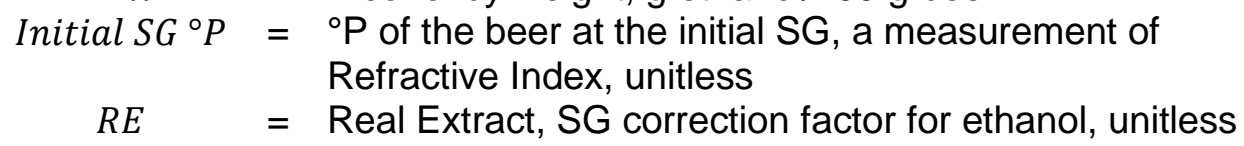

The SG can be converted to ${ }^{\circ} \mathrm{P}$ by (Sato, Equation 4 ):

$$
{ }^{\circ} P=-463.37+668.72(S G)-205.35(S G)^{2}
$$

where: $\quad{ }^{\circ} P=$ Degrees Plato, a measurement of Refractive Index, unitless

and the RE of a sample can be approximated by (Sato, Equation 2):

$$
R E=0.1808\left({\text { Initial } S G^{\circ}}^{\circ}\right)+0.8192\left(\text { Sample } S G^{\circ} P\right)
$$

Further background and theory for this experiment can be found in:

- Fogler, H.S., Elements of Chemical Reaction Engineering, Fifth Edition, Pearson, 2016, pp. 364-381.

- Sato, BK, Alam, U, Dacanay, SJ, Lee, AK, and Shaffer, JF. (2015), "Supplemental Material for Brewing for Students: An Inquiry-Based Microbiology Lab", Journal of Microbiology \& Biology Education, 16(2), pp. 223-229.

\section{Sanitization}

Before beginning the experiment, it is important to understand the importance of sanitization throughout the brewing and fermentation processes. If any bacteria are present in the wort, they will compete with the yeast for the glucose and may even kill the yeast cells. To limit this possibility, adhere to the following:

- Add $0.25 \mathrm{oz}$ of Star San sanitization solution to the fermenter jar during the brewing procedure then fill with water - bubbles will form, just add water until the jar is full of solution

- Pour about $100 \mathrm{~mL}$ of the solution from the fermenter jar into a small beaker - this will be used to sanitize the disposable pipette before taking the initial sample

- Drop the airlock into the fermenter jar and allow the airlock to fill with the solution - this sanitization solution will create the airlock

- When the fermenter jar is needed at the end of the brewing, pour the solution down the drain and while pouring out the solution:

- Pour the sanitization solution over one person's hands, the lid to the fermenter, and in the measuring cup to ensure that these have been sanitized as well

- Make sure to retrieve the airlock from the fermenter

- Place the airlock into the hole on the fermenter lid and the person that had the solution poured over their hands should hold onto the lid until it is ready to be placed onto the fermenter

- There may be a few bubbles left at the bottom of the fermenter; try to get as much liquid/bubbles out as you finish pouring out the solution, however, it is ok if there is some leftover

- DO NOT attempt to dry the inside with a towel

- Before each sample is taken throughout the week:

- Make up a small amount of the sanitization solution in a small beaker in order to sanitize the pipette used to take the sample 
- After opening the lid to the fermenter, try not to breathe or cough into the jar to reduce the risk of contamination

- Do not set the lid on the countertop, hold it without your hands touching the inside portion of it

\section{Experimental Procedure (Base Fermentation)}

1. Boil half a gallon of water

2. Once the water is boiling, add $269 \mathrm{~g}$ of the Pale Ale DME

3. Stir the contents of the pot - be cautious of foam rising in the pot; to reduce foaming, keep stirring or remove the pot from the hot plate

4. Once the foam has receded, referred to as Hot Break, return to a boil and continue boiling for one hour

5. After boiling is complete, cool the pot in an ice bath until the wort reaches $\sim 90^{\circ} \mathrm{F}$

6. Rehydrate $0.3-0.4 \mathrm{~g}$ of yeast in $3-5 \mathrm{~mL}$ of water - Heat the $3-5 \mathrm{~mL}$ of water to $35^{\circ} \mathrm{C}$, sprinkle the yeast on top and allow it to sit for 15 minutes, gently swirl to mix the yeast around and ensure the yeast isn't clumping to the sides of the container, allow it to sit an additional 5 minutes

7. Measure the final volume of the wort using the sanitized measuring cup, transfer to the fermenter, and measure the initial Brix \% using the refractometer

8. Add the rehydrated yeast to the wort, seal the fermenter, and transfer the fermenter to the Distillation Column control room, on the floor in the corner to the right of the computer - this room will then be controlled at $20{ }^{\circ} \mathrm{C}$, the ideal temperature for Pale Ale yeasts to ferment

9. Continue sampling throughout the fermentation process - at least twice a day, preferably with at least 4 hours in between sampling

\section{Analyzing the Beer}

In order to obtain proper results, the beer must be analyzed with Spectrophotometry first, followed by Refractometry. The Spectrophotometry analysis will allow you to determine the concentration of yeast cells present in the beer while the Refractometry analysis will allow you to determine the concentration of glucose left in the beer. The sample needs to be centrifuged before testing with the refractometer since undissolved solids in the beer will produce erroneous results.

1. Carefully remove the lid from the fermenter - avoid excessive shaking/stirring

2. Transfer $5-10 \mathrm{~mL}$ of beer into a clean $15 \mathrm{~mL}$ centrifuge tube

3. Replace the lid of the fermenter and return the fermenter to the control room floor

4. Perform spectrophotometry

5. Centrifuge the remaining sample

6. Perform refractometry

\section{Spectrophotometry Procedure}

1. Calibration (zeroing)

- Turn on the spectrophotometer and select the wavelength of $360 \mathrm{~nm}$, using the wheel to adjust the wavelength

- Zero the unit with a cuvette filled with DI water, resetting the Absorbance to

2. Sample analysis $A=0.000$ by pressing the far-right button

- Transfer $1 \mathrm{~mL}$ of beer from the centrifuge tube into a clean $50 \mathrm{~mL}$ sample tube

- Add $15 \mathrm{~mL}$ of DI water to the sample tube and stir/swirl for 30 seconds to mix 
- Transfer $3 \mathrm{~mL}$ of the solution to a clean cuvette

- Place the cuvette into the spectrophotometer

- Record the absorbance of the sample

- When finished with spectrophotometry, rinse the sample down the drain

\section{Centrifuge Procedure}

1. With the remaining sample in the centrifuge tube, place the lid onto the tube and take the tube to the centrifuge

2. Place the tube into the centrifuge and place another centrifuge tube filled with the same volume of water in the open slot across from the sample's tube

3. Centrifuge the sample for 2 minutes at 4000 RPM

4. After centrifuging the sample, perform refractometry

\section{Refractometry Procedure}

1. Calibrate the refractometer

2. Pipet 2-3 drops of centrifuged beer onto the sample plate of the refractometer and gently close the cover plate

3. Allow 30 seconds for the sample to spread across the sample plate - If bubbles or dry spots are seen when the cover plate is closed, add another drop of beer onto the sample plate until no dry spots remain

4. Raise the refractometer to your eye and point toward a light source

5. Record the Brix \% then clean the refractometer, rinsing the sample and cover plates with DI water then drying with the microfiber cloth located in the refractometer box

\section{Calibration of the Refractometer}

1. Pipet 2-3 drops of DI water onto the sample plate of the refractometer and close the cover plate

2. Allow 30 seconds for the sample to spread across the sample plate

3. Raise the refractometer to your eye and point toward a light source

4. Adjust the screw at the top of the refractometer until the white and blue sections meet at $0.0 \%$

5. Dry the sample and cover plates with the microfiber cloth located in the refractometer box 
Appendix E: Fermentation Procedure Available to Students During the Spring 2020 Unit Ops

$\underline{\text { Lab II Course }}$

\section{Fermentation}

\section{Learning Objectives}

In this lab you will use fermentation to study the effects that different preparation steps have on the overall kinetics of the reaction. The learning objectives of this experiment include:

- Fundamentals of bioreactions

- Use of a refractometer

- Liquid chromatography

- Calculating conversion and yield

\section{Lab Requirements (Experimental Objectives)}

The lab requirements must be completed and discussed/reported in the lab report. For the Fermentation lab, the requirements include:

- Calculate yield/percent conversion

- Compare concentration profiles and kinetics

- Model growth rate using the Monod equation

\section{Lab Options (Questions to be Answered)}

The lab options serve as a guide for deciding what question(s) your experiment will be answering. Note that not all options are created equal. The options can be investigated by slightly altering the provided experimental procedure. The options for this lab include:

- Effects of initial mass of DME

- Effects of heating time

- Effects of filtration

- Effects of initial yeast concentration

- Others with TA approval

\section{Prelab Activity}

The goal of pre-lab day is to prepare for running your experiment. Before leaving on pre-lab day, each group must:

- Sketch P\&ID of equipment

- Perform calibration of the refractometer

- Familiarize yourself with sampling procedures

- Discuss/determine modeling equations with the TA

- Discuss Lab Requirements and Lab Options with the TA

- Complete the task list.

\section{Theory}

In a bioreaction, living cells use enzymes to convert specific reactants into products. The use of bioreactions to create commercial products, from food and medicines to polymers, has grown dramatically in past years. Advantages of bioreactions include relatively high yield, ambient-tomild reaction conditions, and stereospecific product formation. A generic reaction equation for a bioreaction is as follows:

$$
\text { Cells }+ \text { Substrate } \rightarrow \text { More cells }+ \text { Product }
$$


In the case of this experiment, the cells are Baker's yeast cells (Saccharomyces cerevisiae), the substrate is glucose, and the product is ethanol. The glucose is provided by a Dry Malt Extract (DME) of malted barley. The DME is boiled to breakdown the remaining starches from the barley into malt, which is then further broken down into glucose. The yeast cells use the glucose as an energy source as well as a reactant to produce ethanol. The ethanol, however, acts as an inhibitor to the yeast cells in the conversion of glucose, gradually slowing the fermentation process.

The growth rate of the cells throughout the fermentation process, taking into account the product inhibition, can be modeled by the empirical form of the Monod equation (Fogler, Equation 9-55):

$$
r_{g}=k_{o b s} \frac{\mu_{\max } C_{s} C_{c}}{K_{s}+C_{s}}
$$

where: $\quad C_{c}=$ Cell concentration, $\mathrm{g} / \mathrm{L}$

$C_{s} \quad=$ Substrate concentration, $\mathrm{g} / \mathrm{L}$

$k_{\text {obs }}=$ Product inhibition factor, unitless

$K_{S} \quad=$ Monod constant, $\mathrm{g} / \mathrm{L}$

$r_{g} \quad=$ Cell growth rate, $g / L-h$

$\mu_{\max }=$ Maximum specific growth reaction rate, $\mathrm{h}^{-1}$

and the product inhibition factor can be obtained (Fogler, Equation 9-56):

$$
k_{o b s}=\left(1-\frac{C_{p}}{C_{p}^{*}}\right)^{n}
$$

where: $\quad C_{p}=$ Product concentration, $\mathrm{g} / \mathrm{L}$

$C_{p}^{*} \quad=$ Product concentration at which all metabolism stops, $\mathrm{g} / \mathrm{L}$

$n=$ Empirical constant, unitless

The yeast cells will die naturally and if exposed to a toxic substance. Since the stunting affect of the ethanol on the yeast is already being accounted for in the Monod equation, only natural death of the yeast cells needs to be accounted for. The cell death rate is (Fogler, Equation 9/59):

$$
r_{d}=k_{d} C_{c}
$$

where: $\quad k_{d}=$ Natural death rate constant, $\mathrm{h}^{-1}$

$r_{d}=$ Cell death rate, $\mathrm{g} / \mathrm{L}-\mathrm{h}$

When the cells use substrate as an energy source instead of conversion to products, the cell is considered to be maintaining itself. The rate of substrate consumption for maintenance is (Fogler, Equation 9-67):

$$
r_{s m}=m C_{c}
$$

where: $\quad m=\frac{\text { Mass of substrate consumed for maintenance }}{\text { Mass of cells } \cdot \text { time }}, \frac{g \text { substrate }}{g \text { cells } \cdot h}$ 


$$
r_{s m}=\text { Rate of substrate consumption for maintenance, } \mathrm{g} / \mathrm{L}-\mathrm{h}
$$

By combining the above kinetic relationships with yield coefficients, mass balance correlations are able to be formed. Integrating mass balance relationships will result in concentration profiles for the respective chemical species. Comparison between the different concentration profiles and reaction rate profiles between the different conditions and between the different sampling methods can then be carried out.

Further background and theory for this experiment can be found in:

- Fogler, H.S., Elements of Chemical Reaction Engineering, Fifth Edition, Pearson, 2016, p. 364-381.

\section{Experimental Procedure (Base Fermentation)}

1. Boil half a gallon of water

2. Once the water is boiling, add $269 \mathrm{~g}$ of the Pale Ale DME

3. Stir the contents of the pot - be cautious of foam rising in the pot; to reduce foaming, keep stirring or remove from heat

4. Once the foam has receded, return to a boil and continue boiling for one hour

5. After boiling is complete, cool the pot in an ice bath until the wort reaches $\sim 90^{\circ} \mathrm{F}$

6. Rehydrate $0.3-0.4 \mathrm{~g}$ of yeast in $3-5 \mathrm{~mL}$ of water

7. Measure the final volume of the wort, transfer to the fermenter, and take initial samples

8. Add the rehydrated yeast to the wort, seal the fermenter, and transfer the fermenter to the fermentation location

9. Continue sampling throughout the fermentation process

\section{Sampling of the Beer}

In order to obtain proper results, the sampling of the beer must be done in the following order: Spectrophotometry, refractometry, then HPLC. The sample needs to be centrifuged before testing with the refractometer and HPLC since undissolved solids in the beer will skew results.

1. Carefully remove the lid from the fermenter

2. Transfer $5-10 \mathrm{~mL}$ of beer into a clean centrifuge tube

3. Replace the lid and return the fermenter to fermentation location

4. Perform spectrophotometry

5. Perform refractometry

6. Perform HPLC

\section{Spectrophotometry Procedure}

1. Calibration (zeroing)

- Turn on the spectrophotometer and select the wavelength of $360 \mathrm{~nm}$, using the wheel to adjust the wavelength

- Zero the unit by using a blank cuvette filled with DI water, resetting the unit to $A=0$

2. Sample analysis

- Transfer $1 \mathrm{~mL}$ of beer from the centrifuge tube into a clean sample tube

- Add $7 \mathrm{~mL}$ of DI water to the sample tube and stir/swirl to mix

- Transfer $3 \mathrm{~mL}$ of the solution to a clean cuvette

- Place the cuvette into the spectrophotometer

- Record the absorbance of the sample

- When finished with the sample, discard the sample down the drain 


\section{Centrifuge Procedure}

1. With the remaining sample in the centrifuge tube, place the cap onto the tube and take the tube into Dr. Willing's lab

2. Place the tube into the centrifuge and place another centrifuge tube filled with the same volume of water in the open slot across from the sample's tube

3. Centrifuge the sample for 2 minutes at 4000 RPM

4. After centrifuging the sample, transfer the liquid portion of the sample into a clean sample tube

\section{Procedure for Refractometer Sampling}

1. Calibrate the refractometer

2. Pipet 2-3 drops of beer onto the sample plate of the refractometer and close the cover plate

3. Allow 30 seconds for the sample to spread across the sample plate

4. Raise the refractometer to your eye and point toward a light source

5. Record the Brix \% then clean the refractometer

\section{Procedure for High Performance Liquid Chromatography (HPLC) Sampling}

1. Store the remaining sample in the refrigerator located in the AIChE room on the second floor of Ernst Hall

2. After all samples have been collected, set up a meeting time with a research assistant of Dr. Tik's lab

3. Take the samples to Dr. Tik's lab (Lutz 312) and prepare the samples for HPLC analysis with the research assistant

\section{Calibration of the Refractometer}

1. Pipet 2-3 drops of DI water onto the sample plate of the refractometer and close the cover plate

2. Allow 30 seconds for the sample to spread across the sample plate

3. Raise the refractometer to your eye and point toward a light source

4. Adjust the screw at the top of the refractometer until the white and blue sections meet at $0.0 \%$ 